\title{
Numerical Analysis and Deformation Mechanism Study on an Excavated High-Steep Slope of a Hydropower Station
}

\author{
Guangcheng Shi, ${ }^{1,2}$ Yifeng Wang, ${ }^{3}$ Yingkui Wang, ${ }^{4}$ Zhigang Tao ${ }^{1},{ }^{1,2}$ Liangpeng Wan, ${ }^{3}$ \\ and Lanyun $\mathrm{Xi}^{5}$ \\ ${ }^{1}$ State Key Laboratory for Geomechanics and Deep Underground Engineering, \\ China University of Mining \& Technology (Beijing), Beijing 100083, China \\ ${ }^{2}$ School of Mechanics and Civil Engineering, China University of Mining and Technology (Beijing), Beijing 100083, China \\ ${ }^{3}$ China Three Gorges Projects Development Co., Ltd., Chengdu, Sichuan 610041, China \\ ${ }^{4}$ Changjiang Survey, Planning, Design and Research Co., Ltd., Wuhan, Hubei 430010, China \\ ${ }^{5}$ Three Gorges High-Tech Information Technology Co., Ltd., Beijing 100033, China
}

Correspondence should be addressed to Zhigang Tao; taozhigang@263.net

Received 5 February 2020; Revised 28 June 2020; Accepted 8 July 2020; Published 25 July 2020

Academic Editor: Chunshun Zhang

Copyright (c) 2020 Guangcheng Shi et al. This is an open access article distributed under the Creative Commons Attribution License, which permits unrestricted use, distribution, and reproduction in any medium, provided the original work is properly cited.

\begin{abstract}
The high-steep rock slope stability is one of the key technologies in the construction of water conservancy and hydropower projects, which affects and restricts the development of hydraulic resources and the construction of hydropower projects. In this paper, a three-dimensional numerical model was built incorporating stratigraphy, geological structures, and the inverted rock mechanical parameters to perform displacement, stress, and plastic zone analyses for an excavated slope in China using the FLAC3D software. The numerical simulation results after slope excavation show that the deformation near the fault fracture zone is the largest, ranging from $350 \mathrm{~mm}$ to $380 \mathrm{~mm}$. The compressive stress is concentrated on the slope foot and the connecting part, the stress value is $2 \mathrm{MPa} \sim 5 \mathrm{MPa}$, there is a large tensile stress area in the slope, and the tensile stress value is $0 \mathrm{MPa} 0.4 \mathrm{MPa}$. The plastic zone of the slope is concentrated near the fault $\mathrm{F}_{6}$ and the structural influence zone, and the rock mass of the slope basically enters the plastic state. On this basis, the deformation mechanism of slope was analyzed, while the internal and external factors affecting the slope deformation were described in detail. This work would provide an effective reference basis for slope stability evaluation and treatment of similar hydropower stations.
\end{abstract}

\section{Introduction}

The instability of engineering rock mass often causes losses of human lives and infrastructure damage, imposing large financial costs to societies and many potential secondary disasters [1-6], especially the instability of slope engineering. As an example, more than 5000 landslides were reported in China in 2015, resulting in hundreds of deaths and billions of economic losses. Therefore, it was especially important to analyze and evaluate the stability of the high-steep slopes. Among the stability analysis methods for geotechnical engineering, the development of slope stability analysis method is proved to be highly recognized $[7,8]$.
In recent years, an increasing number of scholars have adopted the numerical simulation methods to analyze slope stability, while the typical numerical simulation method has been the FLAC3D strength reduction method, which was based on finite difference [9-11]. Through this method, stress deformation characteristics and the change of plastic area during slope excavation could be effectively analyzed, while slope support measures reasonably would be simulated. This would lead to a comprehensive study on slope stability. Consequently, this method has been widely utilized in both engineering research and design field [12-17].

The stability of high rock slopes constitutes the most important engineering geological and geotechnical problem 
for large-scale water conservancy and hydropower projects [18-21]. The stability control has become a significant key technology for the success or failure of water conservancy and hydropower projects, both affecting and restricting the development of hydropower resources as well as the construction of hydropower projects [22, 23]. However, the appropriate mechanical parameters of slope rock mass constitute the foundation, upon which, the smooth progress of slope stability calculation could be ensured. Through the geological information analysis of the slope in Xiaowan Hydropower Station and according to the deformation and damage in the excavation of the accumulation slope, the shear strength parameters of the accumulation slope were inverted through the rigid limit equilibrium method. Moreover, the deformation parameters of the accumulation slope were inverted based on the monitoring and calculated displacements towards the slope direction regarding the accumulation slope key point [24].

In addition, a high number of scholars have analyzed the stability analysis of slopes of multiple hydropower stations. Through FLAC numerical simulation analysis of the large excavation slope of Liyuan Hydropower Station, the deformation and failure characteristics of the slope under the conditions of excavation and normal water level were obtained, which provided a theoretical basis for the construction and operation of the hydropower station [25]. Based on the slope around the flood discharge tunnel at Yangqu Hydropower Station, a complicated three-dimensional (3D) numerical simulation and safety assessment were implemented in FLAC3D, while 3D slide arcs of good shape were obtained [26]. Taking the right bank slope in Dagangshan Hydropower Station in Sichuan province of China as the research background, the FLAC3D numerical simulation method was utilized to analyze its stability [27-29]. Through the FLAC3D program utilization as a computational analysis tool, the deformation mechanism of the bank slope of the Haizhou Open Pit Coal Mine Hydropower Station lower reservoir was analyzed. The results demonstrated that cyclical fluctuations and speeds of the reservoir water level affected its bank slope stability [30]. In order to study the deformation mechanism and control countermeasures of the high and steep slope at the Huangjinping Hydropower Station on the Dadu River in Sichuan province, the FLAC3D numerical simulation software was used to carry out a comparative study on the distribution of plastic zones prior to and following the slopes reinforcement [31]. In order to comprehensively understand the influence of deep-seated discontinuities on the left slope of Jinping I Hydropower Station and its global stability, both Sarma's method and the strength reduction method based on FLAC3D were adopted to simulate the plastic zone distribution. Also, the results indicated that the deep-seated cracks played a significant role in the slide surface location designation [32]. The time-dependent behavior of the left bank abutment slope at Jinping I Hydropower Station had a major influence on the normal operation and long-term safety of the hydropower station. A geomechanical model containing various faults and weak structural planes was established, while a numerical simulation was conducted under normal water load condition through FLAC3D processing to analyze the slope stability [33-38]. To research the macroscopic deformation of the left bank slope of the Baihetan Hydropower Station in Southwestern China, the unloading deformation of the left bank abutment rock mass was studied through FLAC numerical calculations [39].

In this paper, the left bank slope of the discharge tunnel of Wudongde Hydropower Station was taken as the research object. Based on the recommended values of rock mechanics parameters and slope safety monitoring results, the FLAC3D numerical model was used to inversely analyze the mechanical parameters of the slope rock mass. In addition, based on the results, the stability of the current and excavation slopes was studied, while the displacement field, the stress field, and the plastic zone distribution of four typical sections of the slope were analyzed. Combined with the geological characteristics and the numerical analysis results, the internal and external factors that affected the deformation law of the high-steep rock slope were described in detail. Furthermore, the corresponding treatment measures were put forward to ensure the stability of the slope of Wudongde Hydropower Station.

\section{Engineering Situation}

2.1. Topography and Geomorphology. The Wudongde Hydropower Station dam site was located at the lower reaches of the Jinsha River at the junction of Huidong County in Sichuan Province and Luquan County in the Yunnan Province. It constitutes the first cascade hydropower station in the four cascades of the lower reaches of the Jinsha River (Figure 1). The outlet of the flood discharge tunnel of the hydropower station was located at the left side of the left bank diversion tunnel and of the tail water of the power station. The elevation of the flip bucket was $860 \mathrm{~m}$. A plunge pond was arranged downstream of the flip bucket to dissipate energy, while the plunge pool was formed by the Xiaohuashan platform excavation. The rock mass was discontinued and the impact resistance was poor. The plunge pool was of closed drainage structure type, and the foundation corridor was set to encircle the plunge pool. The bottom of the pond was $795 \mathrm{~m}$ high, $245 \mathrm{~m}$ long, and $110 \mathrm{~m}$ wide.

First, the upper cover of the high slope on the left side of the exit of the flood discharge tunnel was removed. Following, it was excavated to form an artificial slope. The maximum elevation of the overburden was approximately $1070 \mathrm{~m}$, while the highest open line elevation of the slope was approximately $970 \mathrm{~m}$. Also, the excavation elevation of the bottom plunge pool foundation corridor was $786.5 \mathrm{~m}$, and the maximum height of the artificial slope was $183.5 \mathrm{~m}$. The slope above the elevation of $925 \mathrm{~m}$ was dolomite excavation. Moreover, the strike of rock stratum was nearly N-S, the dip angle ranged from $28^{\circ}$ to $35^{\circ}$, and the dip angle of the slope was approximately $80^{\circ}$. The artificial slope was a gentle slope in angle. The artificial slope below $925 \mathrm{~m}$ was the bottom layer of thin dolomite fold, the strike of rock stratum was nearly E-W, the dip angle ranged from $70^{\circ}$ to $85^{\circ}$, and the dip 


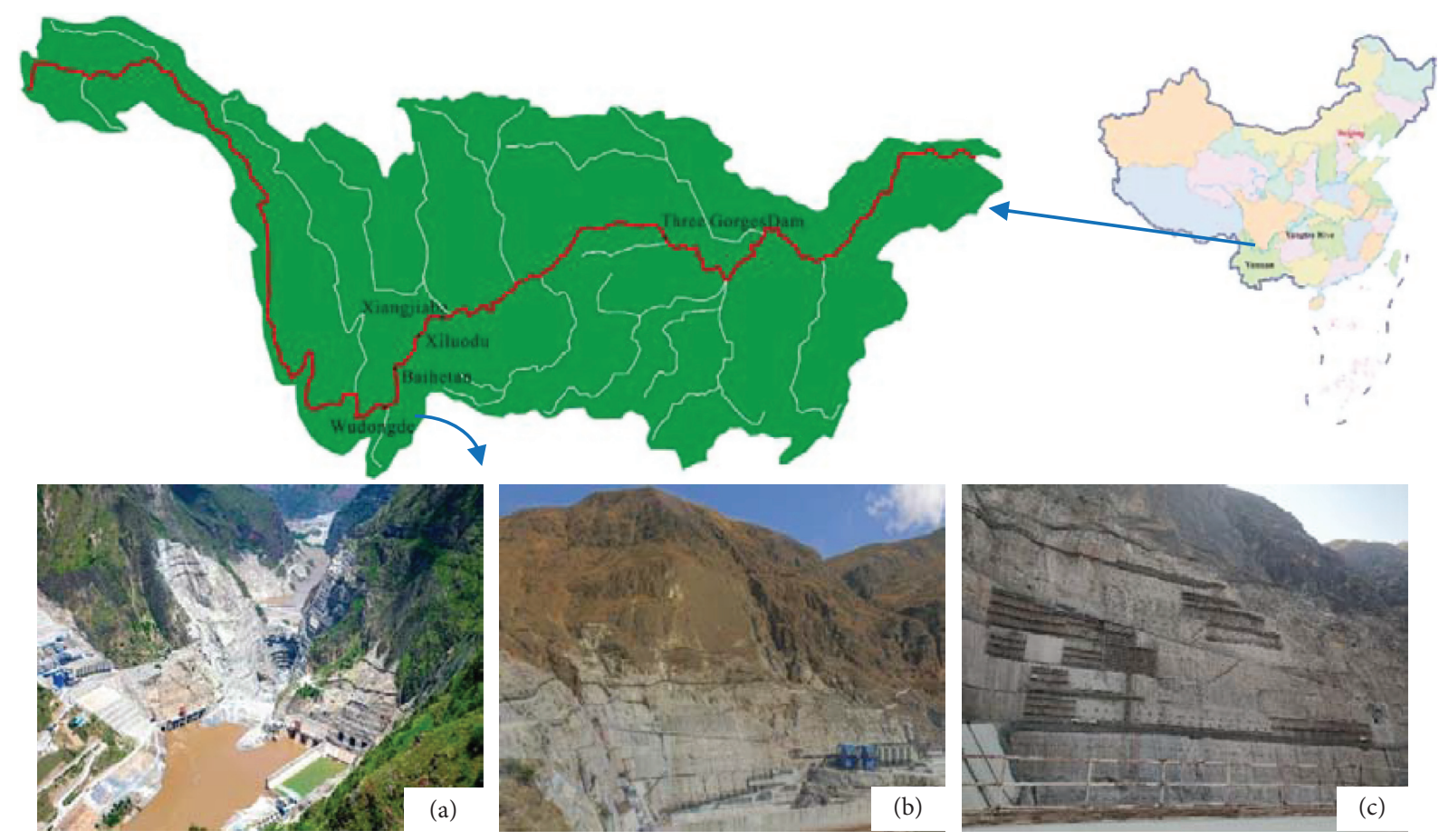

FIgURE 1: Geographical location and field characteristics of Wudongde hydropower station.

angle of the slope was approximately $73^{\circ}$. The artificial slope was steep.

2.2. Formation Lithology. The strata exposed before the excavation were the quaternary Huashangou cumulative body, the folded basement snowfall formation, the sedimentary cover Guanyinya formation, and the Dengying formation:

(1) The total thickness of quaternary Huashangou deposit was approximately $50 \mathrm{~m}-70 \mathrm{~m}$, which could be divided into three layers: the upper part was the collapse deposit gravel layer with a thickness of approximately $20 \mathrm{~m}$; the middle part was the alluvial silty clay layer with a thickness of $10 \mathrm{~m}-26 \mathrm{~m}$; and the lower part was the collapse and alluvial accumulation layer of erratic boulder and gravel with a thickness of $20 \mathrm{~m}-25 \mathrm{~m}$.

(2) The stratigraphic lithology of the Luoxue formation on the folded basement comprised of limestone and dolomite. With $\mathrm{F}_{6}$ of Huashangou fault as the boundary, the upper side was thin interbedded with the 10th Luoxue formation $\left(\mathrm{Pt}_{2 \mathrm{l}}^{10}\right)$ or very thin limestone. Also, the rock mass was hard, while the lower side was with thin interbedded or very thin dolomite of the Luoxue formation $\left(\mathrm{Pt}_{21}\right)$, while the rock was medium-hard. Influenced by the Huashangou fault, wrinkles were developed in the rock mass, while the properties of rocks varied. The strike direction was generally $250^{\circ} \sim 290^{\circ}$, the tendency was $S$, and the dip angle was approximately $70^{\circ} \sim 85^{\circ}$ with local antidip.
(3) The Guanyinya formation $\left(Z_{2 g}\right)$ of sedimentary caprock was mainly composed of gray thin interbedded or very thin dolomite. At the bottom of Guanyinya formation near fault $\mathrm{F}_{6}$, approximately $3 \mathrm{~m} \sim 5 \mathrm{~m}$ of thick carbonaceous shale was found, which was basically composed of medium-hard rock, with poor to fragmented rock mass. The Dengying formation $\left(\mathrm{Z}_{2 \mathrm{~d}}\right)$ was a shallow gray thick and medium-thick dolomite with generally exposed hard to medium hard rock, relatively complete. Sedimentary caprock strata strike was approximately $340^{\circ} \sim 10^{\circ}$, while the tendency was $E$ and the dip angle was $28^{\circ} \sim 35^{\circ}$.

\section{Geological Structure}

The left-side slope of the flood discharge tunnel was penetrated by a large-scale fault $\mathrm{F}_{6}$. The fault $\mathrm{F}_{6}$ was a normal fault, the vertical offset was approximately $420 \mathrm{~m}$, the fault strike was $70^{\circ} \sim 90^{\circ}$, the tendency was $S E$, the inclination angle was approximately $70^{\circ}$, and the fault width was generally $3 \mathrm{~m} \sim 8 \mathrm{~m}$, mainly composed of broken rock. The slope fissures were generally undeveloped but locally developed, mainly constituting the surface fissures. The lengths of the fissures were generally $5 \mathrm{~m} \sim 10 \mathrm{~m}$. The fissures were generally flat and rough, mostly closed or slight. A total of 213 blocks were found in the slope, constituting 153 blocks less than $1000 \mathrm{~m}^{3}$, accounting for $71.9 \%$, while 54 blocks were from $100 \mathrm{~m}^{3}$ to $1000 \mathrm{~m}^{3}$, accounting for $25.3 \%$. Moreover, 6 blocks were from $1000 \mathrm{~m}^{3}$ to $10000 \mathrm{~m}^{3}$, accounting for $2.8 \%$. The maximum bulk volume was approximately $4691 \mathrm{~m}^{3}$. Among these blocks, 12 were basically stable blocks, 187 blocks were 
of poor stability, and 14 blocks were of worst stability. The depth was generally approximately $2 \mathrm{~m} \sim 5 \mathrm{~m}$, and the deepest point was at approximately $29 \mathrm{~m}$. In summary, the overall quality of the rock mass on the left-side slope of the exit of the flood discharge tunnel was poor. The construction site of the left-bank slope project is presented in Figure 2.

Since the left-side slope of the flood discharge tunnel had sustained deformation during the slope excavation, the deformation law and stability of the high-steep slope during the long-term construction of the Wudongde Hydropower Project were the main concerns. Therefore, the stability study of the left-side high slope of the flood discharge tunnel was of high significance for the safe construction and longterm operational safety of the Wudongde Hydropower Project.

\section{Geological and Numerical Models}

Based on the engineering geological conditions exposed by the excavation, an overall 3D geological generalization model of the slope was established based on the geological data. Based on the slope safety monitoring and geophysical prospecting results, the mechanical parameters of slope rock mass were inversely analyzed through a FLAC3D threedimensional numerical model. On this basis, the characteristics of displacement field, stress field, and plastic zone of the left-side slope at the outlet of spillway tunnel under excavation and unloading conditions were studied, while the overall stability of the slope was thoroughly analyzed.

\subsection{Establishment of the Numerical Calculation Model.} According to the actual engineering geological conditions, combined with the distribution of four grades of rock mass and fault, the engineering geological model of the left-bank high slope of the discharge tunnel of Wudongde Hydropower Station was simplified.

A simplified 3D numerical model was constructed based on the actual geological conditions of the left-bank slope of the Wudongde Hydropower Station. The calculation range was $1650 \mathrm{~m} \times 1000 \mathrm{~m} \times 1550 \mathrm{~m}(X \times Y \times Z)$ and the highest elevation was $1760 \mathrm{~m}$, where the $X$-axis was perpendicular to the inner side of the mountain, the $Y$-axis was positive with the parallel slope, pointing to the upstream side, while the $Z$ axis was positive with the vertical direction (right-handed system). Based on the requirements of practical problems and the computational capabilities, the elements of the faults, unloading relaxation zones, and different rock grades in the engineering area should be refined. The physical model of the generalization of the left-side slope is presented in Figure 3.

The model adopts a meshing method combining tetrahedral elements and hexahedral elements. At the bottom and top of the model that are less affected by fault and slope excavation, the hexahedral element grid is used. In complex terrain areas, a tetrahedral cell grid is adopted, which is distributed in a gradual manner. In key research areas such as excavation affected areas and faults, the grid is finely divided, and the grid size is also determined according to the

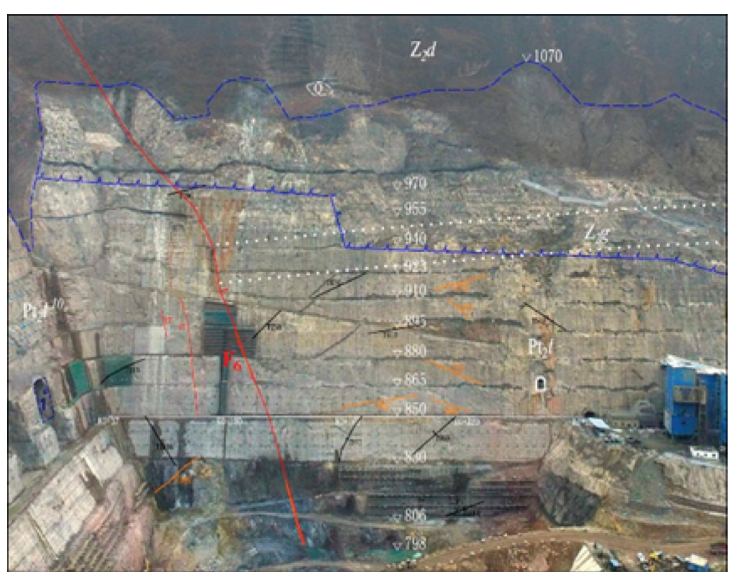

Figure 2: Engineering slope.

size of the volume unit. The model consisted of 753,839 elements and 147,449 nodes. The grid division of the model and the main stratigraphic lithology and structural plane distribution in the study area are shown in Figure 4. For the layered rock mass, a jointed elastic-plastic layer model was adopted, through which the shear failure and tensile failure along the layer and the rock mass could be simulated. In this model, the rock mass strength anisotropy was considered for both directions of the parallel and vertical planes.

Apart from the slope designed as free boundary, the rest of the computation model including bottom and all around is designed as fixed restricting boundary. Under the initial condition and regardless of tectonic stress, only initial stress field produced by weight stress is taken into consideration.

In order to better analyze the evolution law of the rock mass inside the slope, four typical sections were selected for study in the excavation affected area. The typical cross section position is shown in Figure 5.

4.2. Model Mechanical Parameters. Based on the analysis of the internal and external deformation monitoring data of the slope rock mass, combined with the recommended values of the rock mass mechanical parameters provided by the geological survey, the incremental displacement intelligent inversion method was utilized to obtain the mechanical parameters of the rock mass and structural plane of the slope.

The inversion method to obtain the mechanical parameters is as follows: (1) select a number of typical geological profiles on the engineering slope and lay surface and deep displacement monitoring points near the profiles; (2) analyze the on-site displacement monitoring data and select the monitoring data with application value as the inversion data; (3) give the recommended values of the mechanical parameters of the rock mass and determine the parameters to be inverted, namely, the modulus of deformation, cohesion, and coefficient of friction; (4) according to different slope positions, determine different inversion key parameters; (5) set up different comparative working conditions according to the actual project; (6) establish the finite element model of the key section and take the optimization 


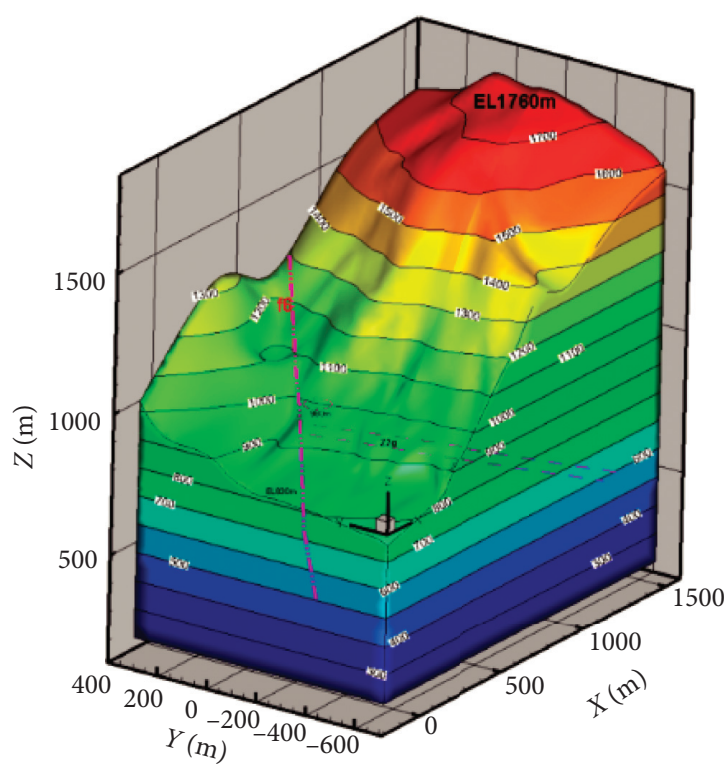

(a)

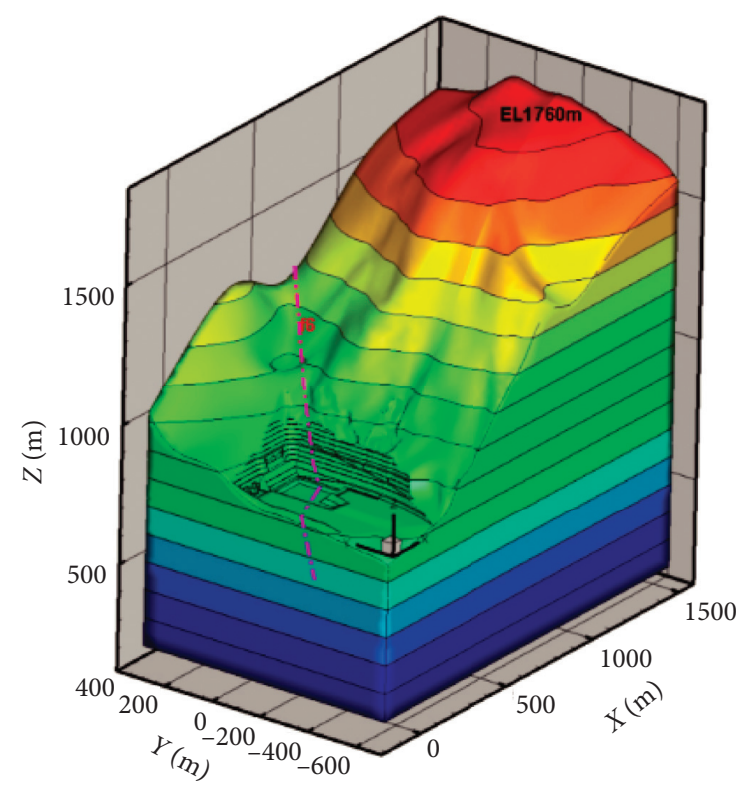

(b)

Figure 3: (a) Slope generalization model before excavation. (b) Slope generalization model after excavation.

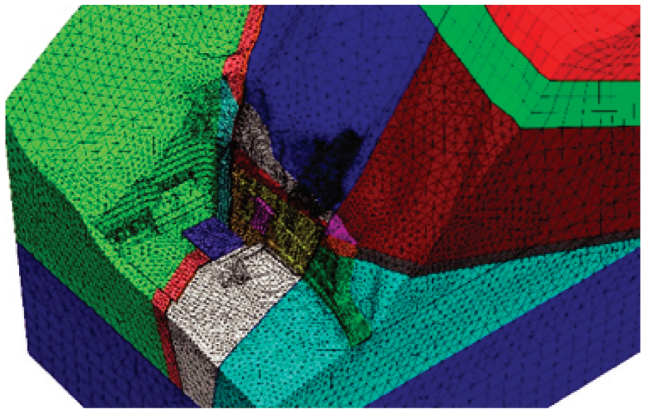

(a)

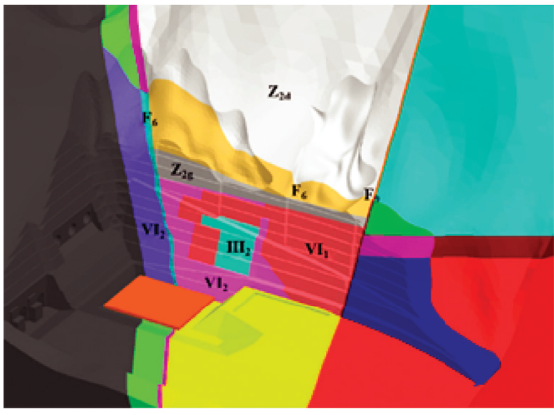

(b)

Figure 4: (a) Grid model after slope excavation. (b) Main stratigraphic lithology and structural plane distribution.

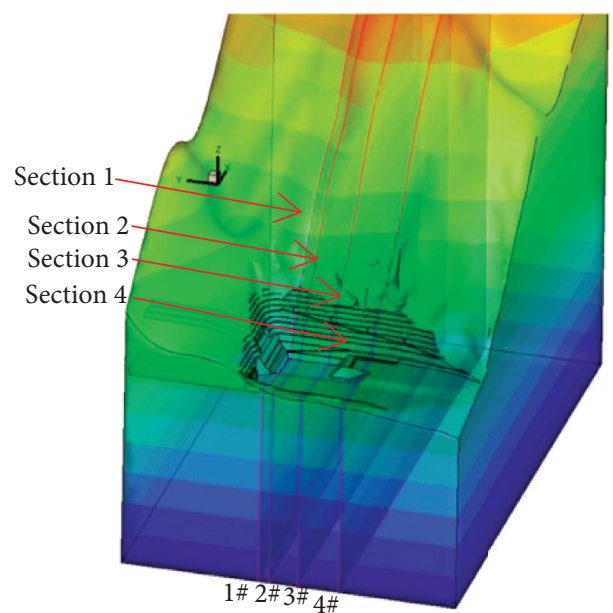

Figure 5: Typical section position of the model. method to invert; (7) compare the calculation results of different sections and different working conditions with the on-site monitoring results. Finally, determine the working conditions in line with the actual situation, and use the mechanical parameters $E, c$, and $f$ of the working conditions as the actual mechanical parameters of the rock mass.

In view of the relaxation effect of rock mass with poor quality caused by excavation of high and steep slope, the quality of rock mass apparently decreased. During the mechanical parameters inversion, the cohesion of relaxed rock mass with large deformation was reduced by $20 \%-50 \%$ of non-unloaded rock mass, while the friction coefficient was reduced by $50 \%-60 \%$ of non-unloaded rock mass. In the model, the deformation modulus, friction coefficient, and cohesion of the rock masses of grades $\mathrm{IV}_{2}, \mathrm{IV}_{1}$, and $\mathrm{III}_{2}$ for $\mathrm{P}_{\mathrm{t} 21}^{10}$ and $\mathrm{P}_{\mathrm{t} 21}$ were mainly inverted. The mechanical parameters of the slope rock mass obtained by inversion are presented in Table 1. 
TABLE 1: Mechanical parameters of slope rock mass.

\begin{tabular}{|c|c|c|c|c|c|c|c|c|c|}
\hline \multirow{3}{*}{ Lithology } & \multirow{3}{*}{$\begin{array}{l}\text { Unloading } \\
\text { relaxation }\end{array}$} & \multirow{3}{*}{$\begin{array}{l}\text { Bulk } \\
\text { density }\end{array}$} & \multirow{2}{*}{\multicolumn{2}{|c|}{$\begin{array}{c}\text { Deformation modulus } E \\
(\mathrm{GPa})\end{array}$}} & \multirow{3}{*}{$\begin{array}{l}\text { Poisson's } \\
\text { ratio } \mu\end{array}$} & \multicolumn{4}{|c|}{ Shear strength } \\
\hline & & & & & & \multicolumn{2}{|c|}{$f$} & \multicolumn{2}{|c|}{$c(\mathrm{MPa})$} \\
\hline & & & $\begin{array}{l}\text { Geological } \\
\text { suggestion }\end{array}$ & $\begin{array}{l}\text { Inversion } \\
\text { parameter }\end{array}$ & & $\begin{array}{l}\text { Geological } \\
\text { suggestion }\end{array}$ & $\begin{array}{l}\text { Inversion } \\
\text { parameter }\end{array}$ & $\begin{array}{l}\text { Geological } \\
\text { suggestion }\end{array}$ & $\begin{array}{l}\text { Inversion } \\
\text { parameter }\end{array}$ \\
\hline \multirow{2}{*}{$\mathrm{Pt}_{21}^{10}\left(\mathrm{IV}_{2}\right)$} & $\begin{array}{c}\text { Non- } \\
\text { unloaded }\end{array}$ & 26.8 & $1-2$ & 2 & 0.33 & $0.5-0.7$ & 0.7 & $0.2-0.4$ & 0.4 \\
\hline & Unloaded & 26.6 & - & 1 & 0.35 & - & 0.42 & - & 0.2 \\
\hline \multirow{2}{*}{$\mathrm{Pt}_{21}^{10}\left(\mathrm{IV}_{1}\right)$} & $\begin{array}{l}\text { Non- } \\
\text { unloaded }\end{array}$ & 26.8 & $3-5$ & 5 & 0.3 & $0.7-0.8$ & 0.7 & $0.4-0.7$ & 0.7 \\
\hline & Unloaded & 26.7 & - & 2.5 & 0.33 & - & 0.42 & - & 0.35 \\
\hline \multirow{2}{*}{$\mathrm{Pt}_{21}^{10}\left(\mathrm{III}_{2}\right)$} & $\begin{array}{l}\text { Non- } \\
\text { unloaded }\end{array}$ & 26.8 & $5-7$ & 7 & 0.26 & 0.40 .9 & 1 & $0.7-0.9$ & 1 \\
\hline & Unloaded & 26.7 & - & 4 & 0.3 & - & 0.8 & - & 0.7 \\
\hline \multirow[t]{2}{*}{$\mathrm{Pt}_{21}\left(\mathrm{IV}_{2}\right)$} & $\begin{array}{l}\text { Non- } \\
\text { unloaded }\end{array}$ & 26.8 & $1-2$ & 2 & 0.33 & $0.5-0.7$ & 0.7 & $0.2-0.4$ & 0.4 \\
\hline & Unloaded & 26.6 & - & 1 & 0.35 & - & 0.42 & - & 0.2 \\
\hline \multirow[t]{2}{*}{$\mathrm{Pt}_{21}\left(\mathrm{IV}_{1}\right)$} & $\begin{array}{c}\text { Non- } \\
\text { unloaded }\end{array}$ & 26.8 & $3-5$ & 5 & 0.3 & $0.7-0.8$ & 0.7 & $0.4-0.7$ & 0.7 \\
\hline & Unloaded & 26.7 & - & 2.5 & 0.33 & - & 0.42 & - & 0.35 \\
\hline \multirow{2}{*}{$\mathrm{Pt}_{21}\left(\mathrm{III}_{2}\right)$} & $\begin{array}{l}\text { Non- } \\
\text { unloaded }\end{array}$ & 26.8 & $5-7$ & 7 & 0.26 & $0.8-0.9$ & 1 & $0.7-0.9$ & 1 \\
\hline & Unloaded & 26.7 & - & 4 & 0.3 & - & 0.8 & - & 0.7 \\
\hline \multirow{2}{*}{$\mathrm{Z}_{2 \mathrm{~g}}\left(\mathrm{IV}_{2}\right)$} & $\begin{array}{l}\text { Non- } \\
\text { unloaded }\end{array}$ & 26.8 & $1-2$ & 2 & 0.33 & $0.5-0.7$ & 0.7 & $0.2-0.4$ & 0.4 \\
\hline & Unloaded & 26.6 & - & 1 & 0.35 & - & 0.42 & - & 0.2 \\
\hline \multirow{2}{*}{$\begin{array}{l}\text { Huashangou } \\
\text { fault cataclasite- } \\
\text { crushed stone }\end{array}$} & $\begin{array}{l}\text { Non- } \\
\text { unloaded }\end{array}$ & 26.6 & 1 & 1 & 0.33 & 0.5 & 0.5 & 0.2 & 0.2 \\
\hline & Unloaded & 26.6 & - & 0.6 & 0.35 & - & 0.25 & - & 0.1 \\
\hline \multicolumn{2}{|c|}{$\begin{array}{l}\text { Huashangou fault-clay mingled } \\
\text { with debris }\end{array}$} & 20 & 0.15 & 0.15 & 0.36 & $0.25-0.35$ & 0.25 & $0.01-0.05$ & 0.01 \\
\hline \multirow{2}{*}{\multicolumn{2}{|c|}{$\mathrm{P}_{3 \mathrm{em}}$ and $\mathrm{P}_{2 \mathrm{y}}$}} & 27.3 & $5-7$ & 10 & 0.3 & $0.8-0.9$ & 1 & $0.7-0.9$ & 1 \\
\hline & & 27 & $14-18$ & 18 & 0.25 & $1.0-1.2$ & 1.2 & $1.2-1.4$ & 1.4 \\
\hline \multicolumn{2}{|c|}{$\mathrm{J}_{2 \mathrm{x}}, \mathrm{J}_{1}$, and $\mathrm{T}_{3 \mathrm{bg}}$} & 27 & $5-10$ & 10 & 0.28 & $0.8-1$ & 1 & $0.5-0.7$ & 1 \\
\hline
\end{tabular}

\section{Numerical Analysis of Slope Stability}

5.1. Displacement Field. As it can be observed from Figures 6 and 7, as the slope was continuously excavated, the height of the slope increased. Particularly, with the excavation of the middle and lower rock masses, the excavation and unloading relaxation of the middle and lower slopes weakened the supporting effect on the upper rock masses, while the magnitude of the slope displacement gradually increased. The deformation vector of the slope rock mass appeared to be outward and demonstrated a downward deformation tendency, while the horizontal displacement outside the slope exceeded both the vertical displacement and the upward and downstream displacements. In addition, the shallow surface layer of the slope was loosened due to excavation and unloading, while the rock mass displacement in this area exceeded the deep displacement, which gradually decreased within the slope. The part with large deformation of the slope was located at the hanging wall and foot wall of fault $\mathrm{F}_{6}$ and the rock mass of grade $\mathrm{IV}_{2}$ was of poor quality below $830 \mathrm{~m}$. Among these, the fault $\mathrm{F}_{6}$ steeply leaned to the slope interior, while the deformation of the upper rock mass was significantly higher compared to the lower rock, which exerted a squeezing effect on the fault and the lower rock mass, whereas the lower rock slope provided the reverse resistance. However, when the middle and lower sides of the slope were weakened, the poor rock mass was excavated and the slope was unloaded. The rock mass and mechanical parameters were reduced, while the upper part of the slope was deformed by the upper part pull and the upper part displayed an outward sinking deformation.

The deformation of grade $\mathrm{IV}_{2}$ rock mass in the hanging wall and footwalls of fault $\mathrm{F}_{6}$ on the slope was generally $200 \mathrm{~mm} \sim 350 \mathrm{~mm}$. Certain footwalls were severely affected by fault $\mathrm{F}_{6}$ and fault fracture zone, while the regional deformation was of $350 \mathrm{~mm} 380 \mathrm{~mm}$. The slope, in an entity, was mainly deformed towards the horizontal direction $(X-$ direction), while it was horizontally directed to the slope exterior. The area with a high amount of deformation was on both sides of fault $\mathrm{F}_{6}$, in between $910 \mathrm{~m}$ and $800 \mathrm{~m}$ in elevation, while the deformation was of $250 \mathrm{~mm}$ to $350 \mathrm{~mm}$. Among these areas, the deformation area of the upper wall of fault $\mathrm{F}_{6}$ was relatively high, mainly because the rock mass on the upper wall of fault $\mathrm{F}_{6}$ was mainly of grade $\mathrm{IV}_{2}$. Also, the distribution area was wide, while following the excavation and unloading of the slope, stress relaxation of the existing 


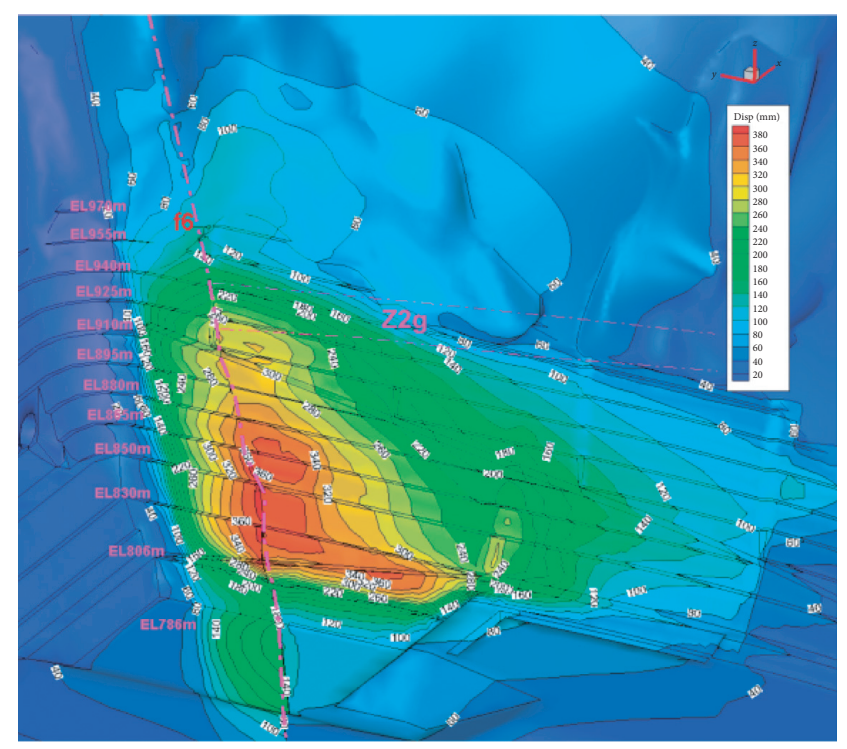

(a)

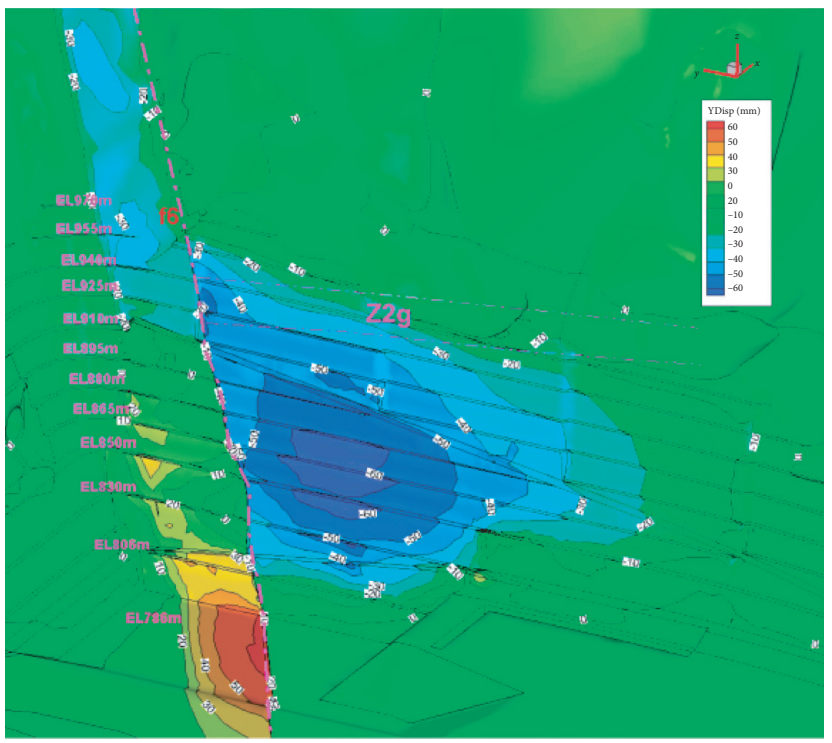

(c)

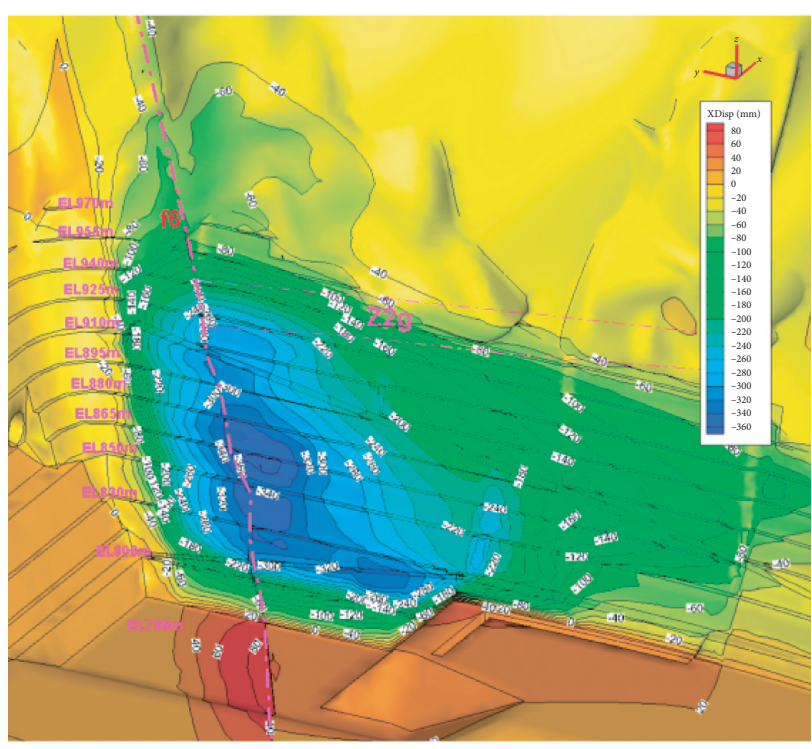

(b)

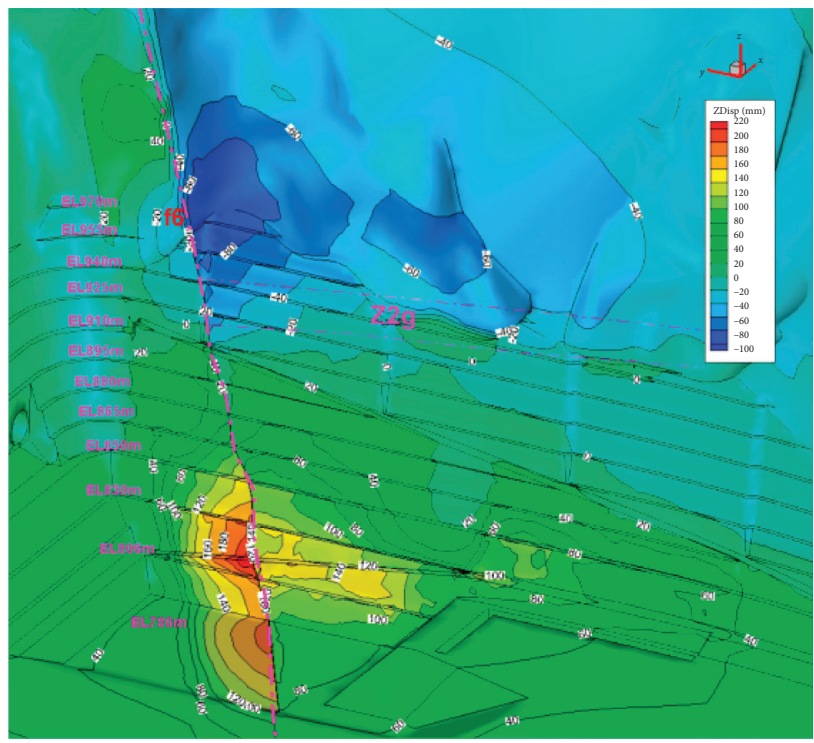

(d)

Figure 6: Variation characteristics of displacement field after excavation. (a) Integral displacement field of slope. (b) Displacement field of slope in $X$-direction. (c) Displacement field of slope in $Y$-direction. (d) Displacement field of slope in $Z$-direction.

slope rock mass occurred along with horizontal deformation outward of the slope. The amount of deformation in the direction of the slope parallel to the slope ( $Y$-direction) was $-50 \mathrm{~mm} \sim 68 \mathrm{~mm}$. The deformation area was mainly distributed on the hanging wall of fault $\mathrm{F}_{6}$, which demonstrated that the hanging wall rock of $\mathrm{F}_{6}$ was deformed towards the downstream side. Among these, the maximum deformation was $60 \mathrm{~mm} \sim 68 \mathrm{~mm}$, located at an elevation of $850 \mathrm{~m} \sim 865 \mathrm{~m}$, mainly because the rock mass in this area was of poor quality, while it was constrained by the foot wall and the rock mass on the front side of the spillway tunnel. Consequently, after the slope rock mass was unloaded, the parallel slope could only deform downstream. For the footwall rock of $F_{6}$, the overall deformation in the direction of the parallel slope was low, while only a portion of the grade $\mathrm{IV}_{2}$ rock mass was deformed upstream by the gravity and deformation of the overlying rock. In addition, the height drop the deformation was higher, while the maximum deformation at the elevation of $806 \mathrm{~m}$ was approximately $42 \mathrm{~mm}$. For the deformation in the vertical direction ( $Z$-direction) of the slope, the subsidence deformation from the elevation of $910 \mathrm{~m}$ to the rock mass at the top of the slope was mainly $40 \mathrm{~mm} \sim 100 \mathrm{~mm}$; the settlement gradually decreased from top to bottom, while the deformation in this area was mainly affected by the gravity of the slope rock mass subsequently to excavation. The middle and lower slopes were characterized by upward deformation and mainly located at the lower plate of fault $\mathrm{F}_{6}$. The corresponding deformation was approximately $50 \mathrm{~mm} \sim 170 \mathrm{~mm}$. Among these, the intersection between the berm at elevation of $813 \mathrm{~m}$ and the fault had sustained the highest upward 

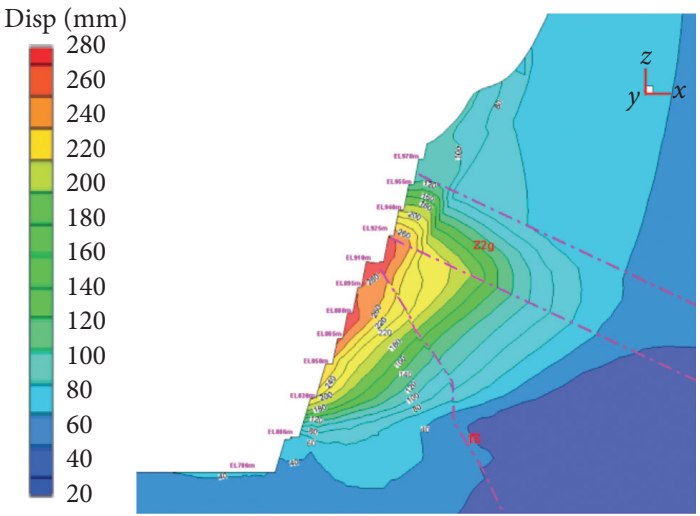

(a)

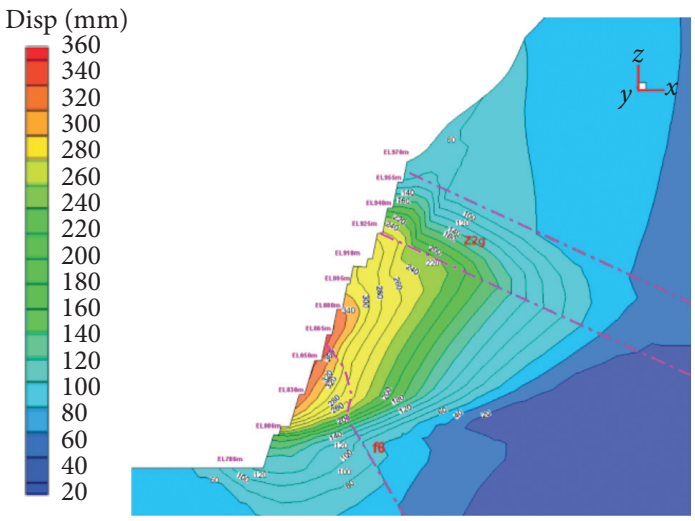

(b)

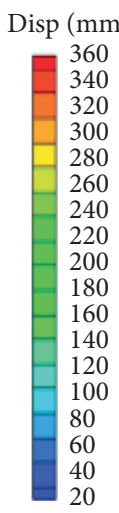

sp $(\mathrm{mm})$
360
340
320
300
280
260
240
220
200
180
160
140
120
100
80
60
40
20
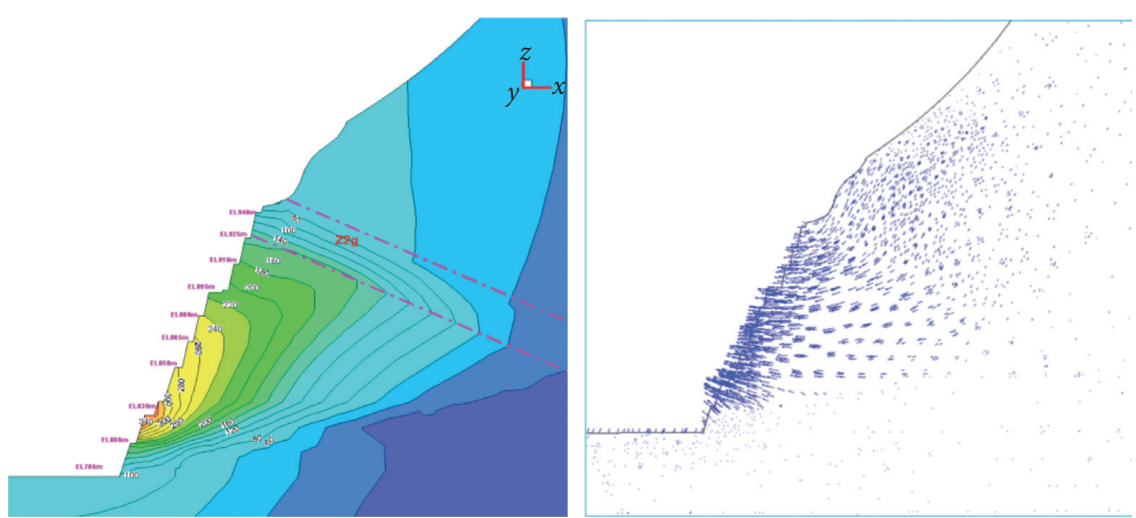

(c)
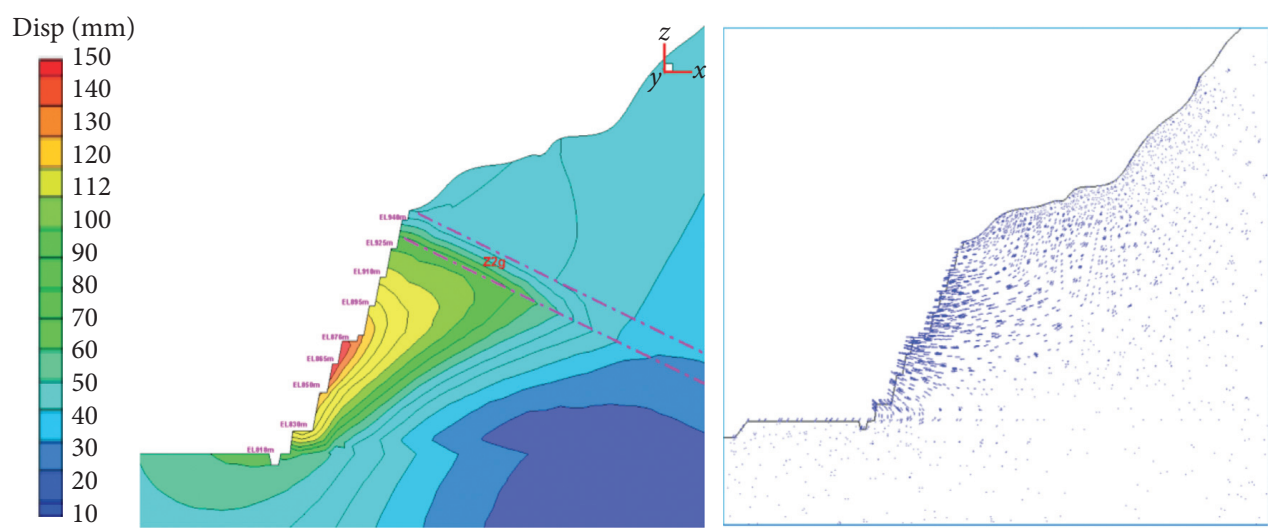

(d)
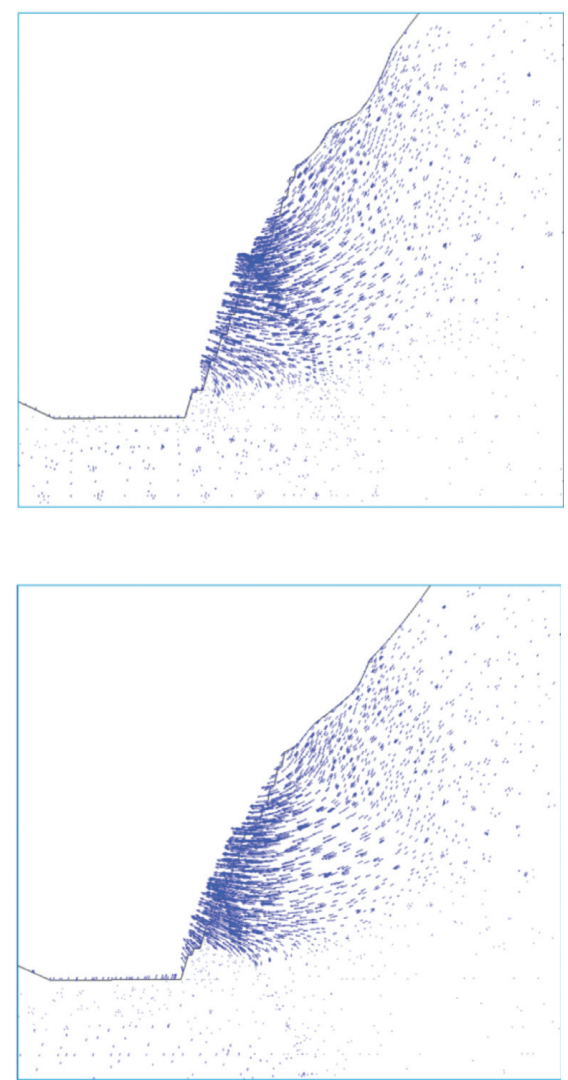
deformation of $240 \mathrm{~mm}$ in length. The deformation of the rock mass in this area occurred mainly due to the deformation rebound caused by the excavation of the overlying rock mass.

Figure 7 presents the displacement cloud diagrams of 4 typical sections following the slope excavation. Through the displacement cloud diagrams comparison of the rock masses of sections 1 and 2, the following conclusions were drawn: the maximum displacement of section 1 was approximately $280 \mathrm{~mm}$, located at an elevation of $925 \mathrm{~m} \sim 865 \mathrm{~m}$. Near the hanging wall and foot wall of the fault $\mathrm{F}_{6}$, the maximum displacement of section 2 was approximately $360 \mathrm{~mm}$, located near the hanging wall and foot wall of the fault $\mathrm{F}_{6}$ with an elevation of $865 \mathrm{~m} \sim 850 \mathrm{~m}$, while the two parts with high deformation were all of grade $\mathrm{IV}_{2}$ rock masses. It could be observed that although the geological structure, stratum lithology, and rock mass quality of the two areas were similar, the maximum deformation amount varied highly, due to different elevations, which indicated that the excavation depth had a significant influence on the unloading deformation of the slope under similar conditions. The higher the excavation depth was, the higher the amount of rebound deformation generated by the slope was. Through the displacement cloud diagrams comparison of sections 3 and 4 rock masses, it could be concluded that the rock masses of the two sections were not penetrated by fault $\mathrm{F}_{6}$, while the rock mass was good. Consequently, the overall deformation of the slope was relatively low. The maximum deformation of section 3 was approximately $240 \mathrm{~mm}$, located near the elevation of $830 \mathrm{~m}$. The mass of this part was $\mathrm{IV}_{2}$ and the depth of the slope was high. Therefore, this part of the rock body sustained high rebound deformation subsequent to excavation and unloading. The maximum deformation of section 4 was approximately $150 \mathrm{~mm}$, located near the elevation of $876 \mathrm{~m}$. The mass of this part of the rock mass was grade $\mathrm{IV}_{1}$, but because the excavation depth of this part of the slope was shallow and restricted by the downstream mountain mass, the overall deformation of this section was low. In summary, the overall deformation of sections 1 and 2 of rock mass was significantly higher compared to other sections, while the area with high deformation was mainly located near the hanging wall and footwall of the fault $\mathrm{F}_{6}$, which indicated the grade $\mathrm{IV}_{2}$ rock in the hanging wall and footwall areas of the $\mathrm{F}_{6}$ slope fault. The body was subjected to disturbances under the action of excavation unloading, while the deformation of the rock mass was also significant. In addition, the shallow surface layer of the slope was loosened due to excavation unloading, while the rock mass deformation in this area exceeded the deep deformation. Moreover, the deformation tended to decrease as the slope depth increased.

5.2. Stress Field Analysis. The geological conditions of the left-side slope at the outlet of the spillway tunnel of Wudongde Hydropower Station were complex. Consequently, the stress field of the slope was relatively complex. The natural stress field of the slope was mainly controlled by the gravity of the slope and the geological structure. After the slope excavation, the slope was unloaded and relaxed, while the relaxation range was approximately distributed along the slope surface. The general depth of stress disturbance was $30 \mathrm{~m}$ to $60 \mathrm{~m}$. After slope excavation, a certain degree of compressive stress concentration existed at the foot and at the junction of the slope. The stress magnitude was approximately $2 \mathrm{MPa}$ to $5 \mathrm{MPa}$, while the local junction of the two slopes reached $12 \mathrm{MPa}$ (Figures 8-10). Figure 8 presents the stress field characteristics of the left-side slope of the outlet of the spillway tunnel under natural stress. The initial stress field had the following characteristics:

(1) Maximum principal stress: it could be observed from the cloud diagram that the maximum principal stress field of the slope increased with depth from the surface to the interior of the slope in the natural state. The maximum principal stress ranged from 0 to $40 \mathrm{MPa}$ and uniformly varied with depth. At the top and foot of the slope, due to the influence of weathering and unloading, a few tension stress zones appeared, but the influence depth was relatively shallow, which indicated that the slope was in a state of stress stability under natural conditions. At the foot of the slope, due to the influence of fault $F_{6}$, a local stress mutation occurred, but its influence depth was shallow and the scope was small, which did not affect the stability of the slope in its natural state

(2) Minimum principal stress: it could be obtained from the cloud diagram that in natural state, the minimum principal stress increased as the elevation decreased, while the overall change trend was more uniform. Its magnitude range was $1 \mathrm{MPa}$ to $11 \mathrm{MPa}$. The minimum principal stress in the shallow part of the slope mostly ranged between 0 and $1 \mathrm{MPa}$, which indicated that the surface of the slope was in tension stress state, due to weathering and unloading. Similarly, in the fault $\mathrm{F}_{6}$ area at the foot of the slope, a small range of stress mutation existed, but it did not affect the overall stability of the slope.

After the slope was completely excavated, the slope was unloaded and relaxed, while the relaxation range was roughly distributed along the slope. The general stress disturbance depth was $30 \mathrm{~m}$ to $60 \mathrm{~m}$. A certain amount of compressive stress concentration existed at the foot and boundary parts of the slope. The stress level was approximately $2 \mathrm{MPa}$ to $5 \mathrm{MPa}$, and the junction of the two slopes reached $12 \mathrm{MPa}$ (Figure 9). A large range of tension stress area existed within the slope, which mainly occurred on all levels of slope surface, while the tension stress of the slope was generally $0 \mathrm{MPa}$ to $0.4 \mathrm{MPa}$. Also, the maximum tension stress value was $1 \mathrm{MPa}$, while the larger part of tension occurred near the slope opening line and the junction area, where the lithology highly changed. The maximum and minimum principal stresses of the four typical sections are presented in Figure 10.

5.3. Strain Zone Analysis. The scope and depth of the plastic zone of the slope were relatively high. The plastic zone of the rock mass gradually increased with excavation. The plastic 


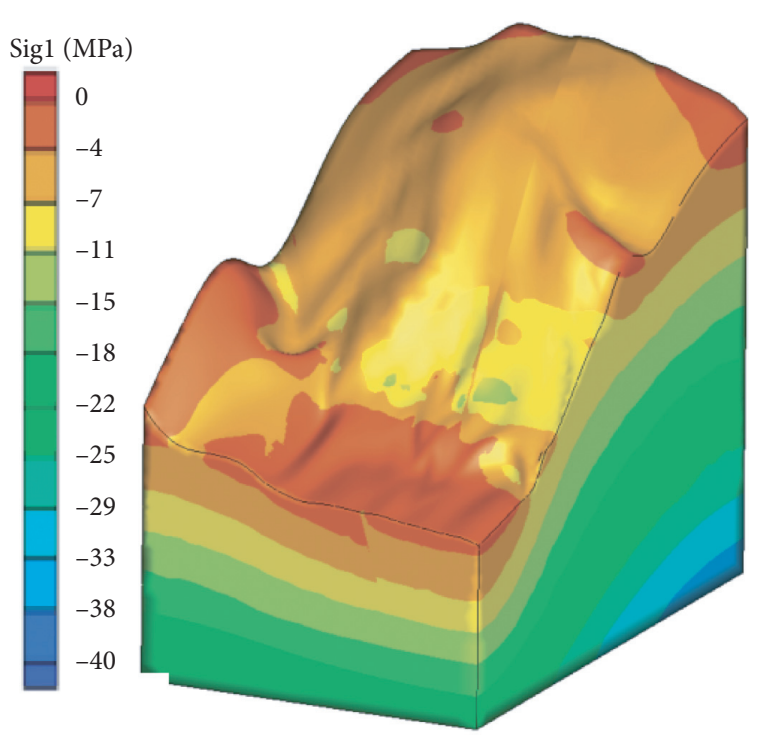

(a)

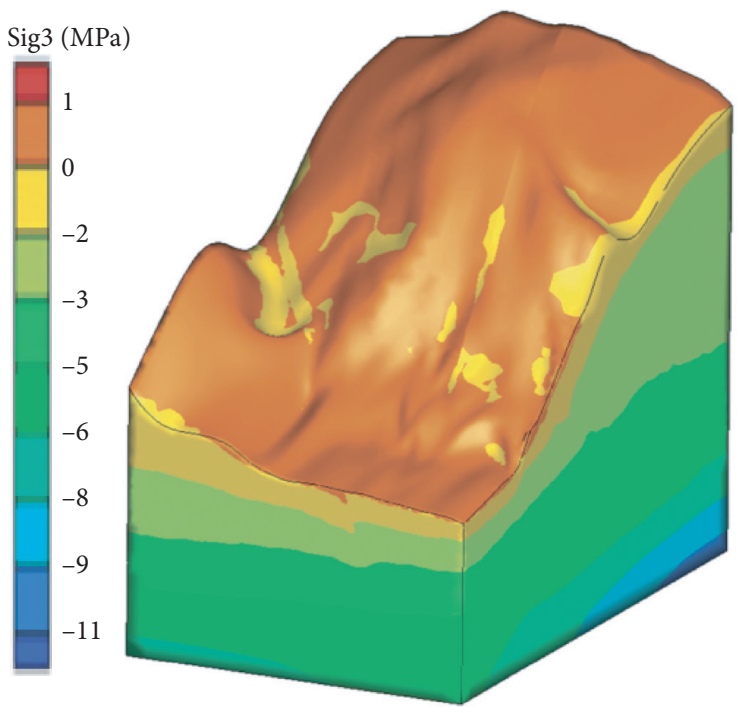

(b)

FIGURE 8: Cloud diagram of (a) maximum principal stress and (b) minimum principal stress of slope in natural state.

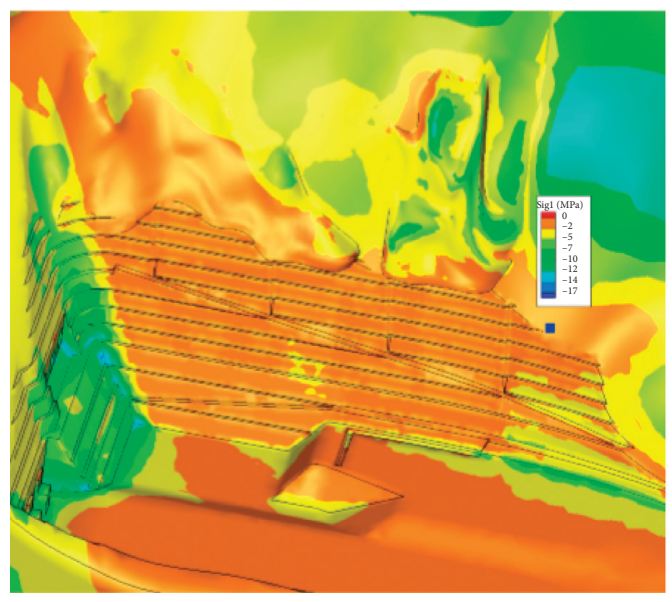

(a)

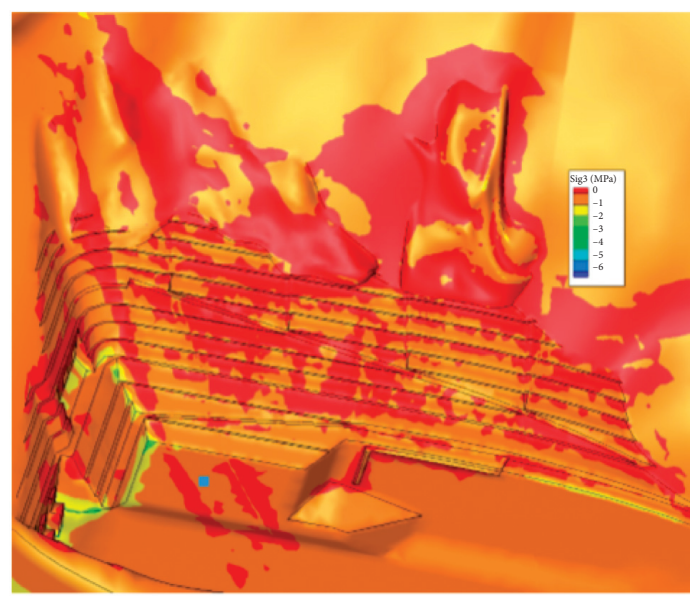

(b)

FIGURE 9: Cloud diagram of (a) maximum principal stress and (b) minimum principal stress of slope after excavation.

zone was mainly distributed on the excavated slope surface. The plastic zone was concentrated on the fault $\mathrm{F}_{6}$ and the tectonic influence zone. The rock mass basically entered the plastic state, mainly as compression-shear failure. Tensionshear failure occurred on the surface of faults and slopes and local rock masses, as presented in Figure 11.

\section{Deformation Mechanism of Slope and Reinforcement Suggestions}

6.1. Slope Deformation Evolution. The process of excavation and unloading of engineering slope is always accompanied by stress adjustment, deformation response, and damage of rock mass. On the one hand, the rock mass of the slope was subjected to dynamic damage caused by blasting. On the other hand, excavation changed the boundary conditions of the slope, and the rock mass sustained unloading deformation. During the long-term geological evolution, strain energy accumulated within the rock mass of the slope, while the slope was in a relatively stable state prior to engineering activities. The excavation disturbed the initial state of the slope, and the rock mass was adjusted accordingly. A certain amount of strain energy, accumulated previously, was released, whereas another amount was transferred to the deep part of the rock mass, resulting in stress redistribution and accompanied by the deformation of the slope. The excavation resulted in strain energy release and unloading relaxation. The instantaneous deformation caused by unloading was rebound, which produced static and dynamic disturbance to the slope and rock mass, causing the opening and dislocation of the original structural planes in rock mass, as well as the expansion of primary joints or new cracks, 


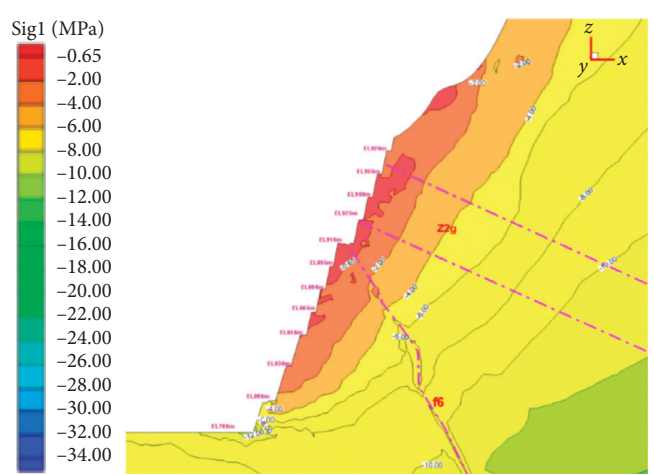

(a)

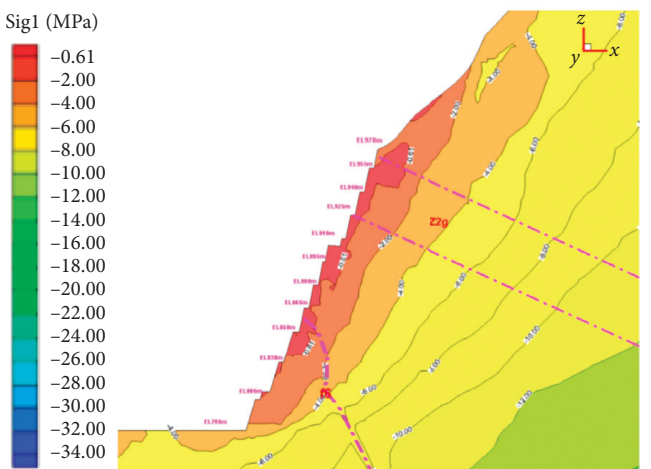

(c)

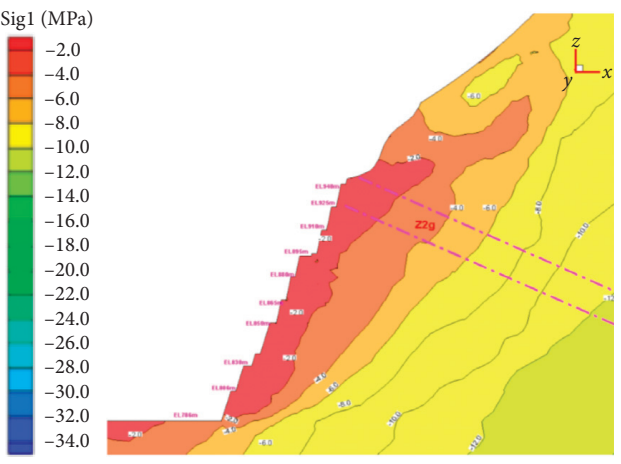

(e)

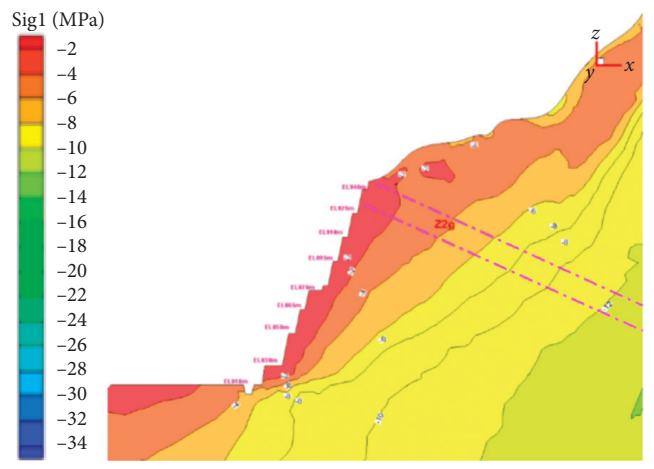

(g)

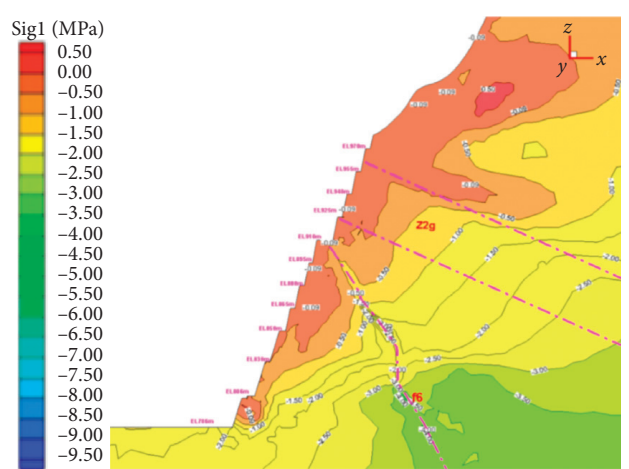

(b)

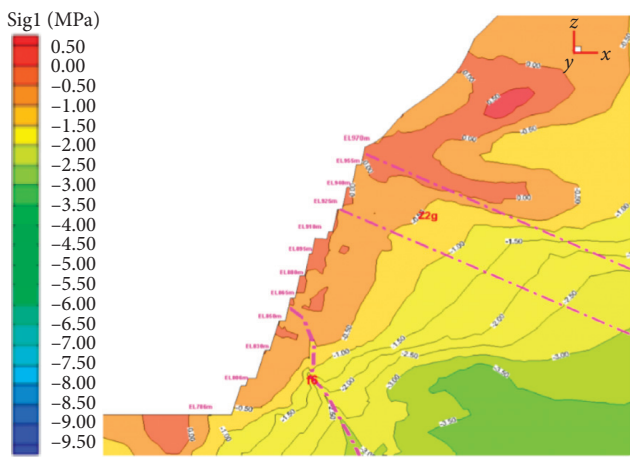

(d)
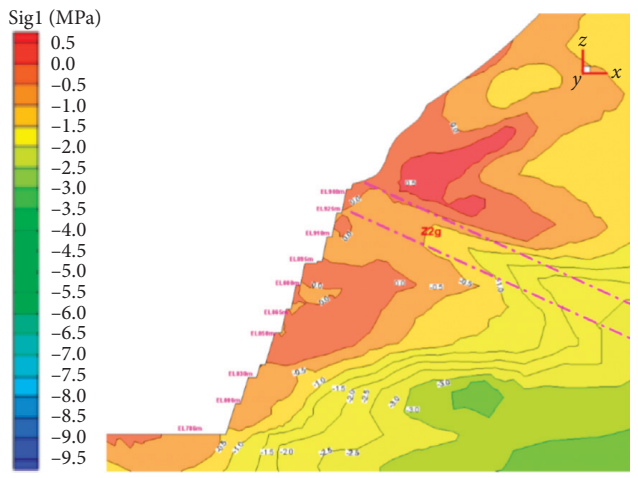

(f)
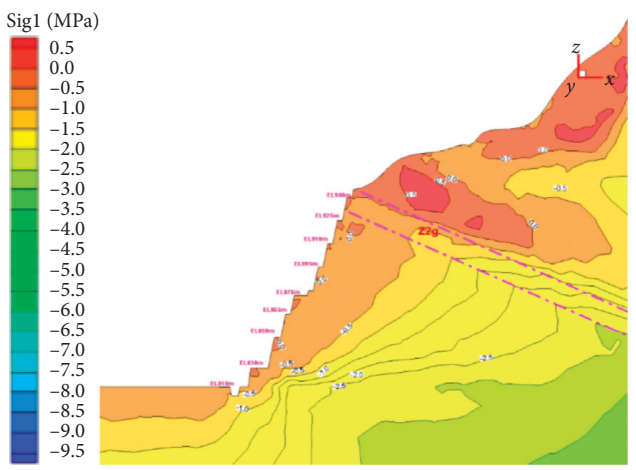

(h)

FIGURE 10: Cloud diagram of maximum principal stress and minimum principal stress of typical sections after excavation. (a) Cloud diagram of maximum principal stress of section 1. (b) Cloud diagram of minimum principal stress of section 2. (c) Cloud diagram of maximum principal stress of section 2. (d) Cloud diagram of minimum principal stress of section 2. (e) Cloud diagram of maximum principal stress of section 3. (f) Cloud diagram of minimum principal stress of section 3. (g) Cloud diagram of maximum principal stress of slope of section 4. (h) Cloud diagram of minimum principal stress of slope of section 4. 


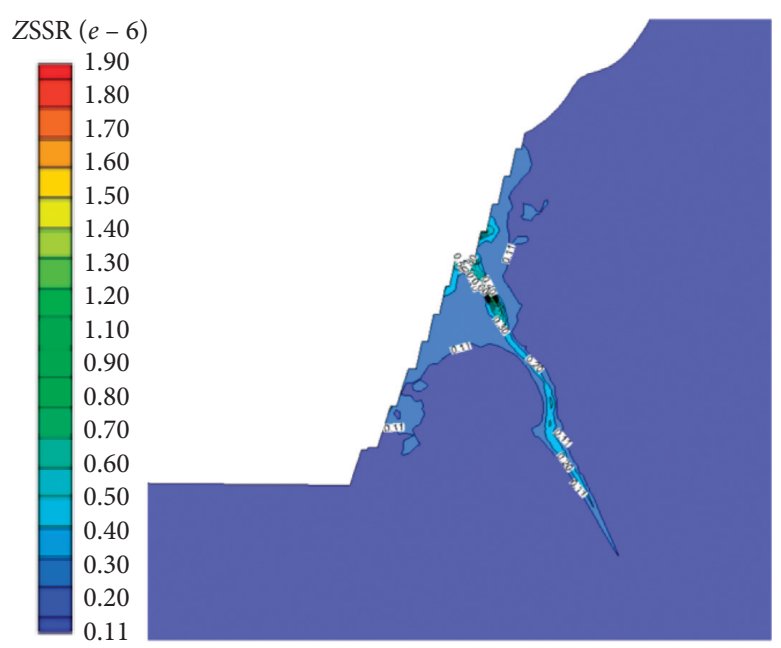

(a)

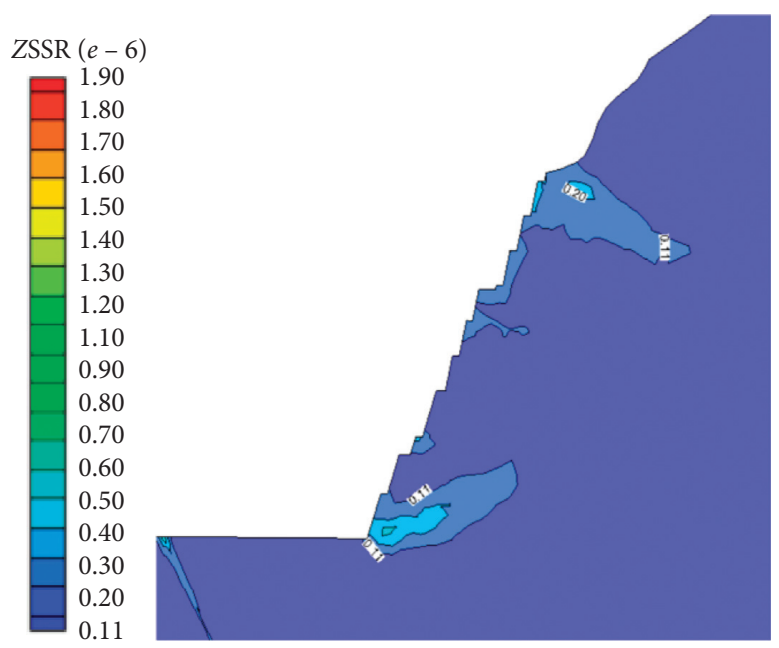

(c)

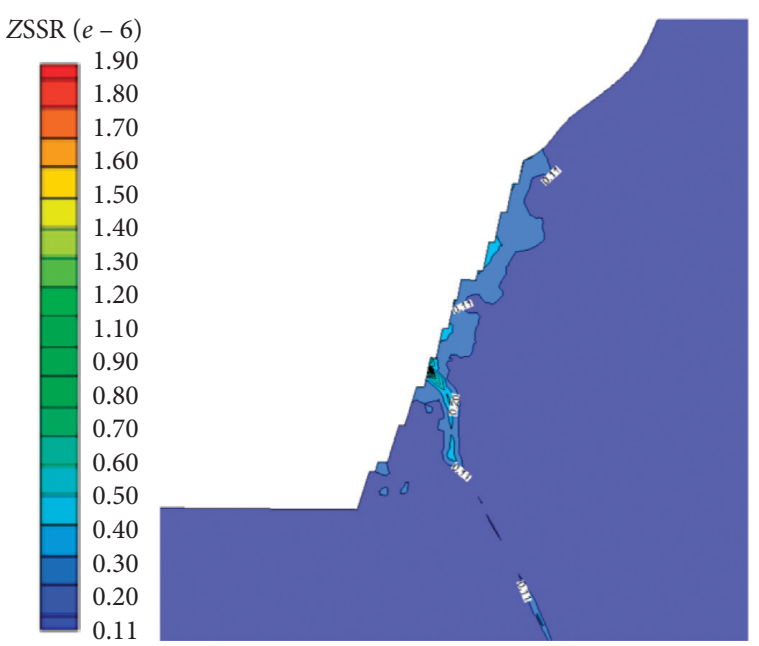

(b)
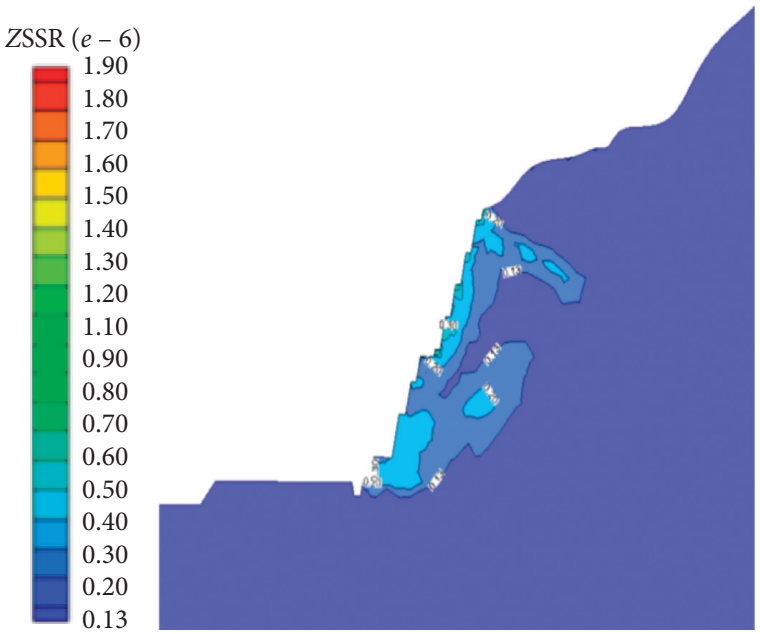

(d)

Figure 11: Plastic area cloud diagram of typical sections after excavation. (a) Cloud diagram of plastic area of section 1. (b) Cloud diagram of plastic area of section 2. (c) Cloud diagram of plastic area of section 3. (d) Cloud diagram of plastic area of section 4.

especially near the geological weak planes, such as faults and lithology, soft rock, and strong unloading relaxation zone. The quality, the mechanical parameters, the bearing capacity, and the stability of retained rock mass might be significantly reduced.

The evolution of slope deformation was microdamage and rupture development of rock mass, along with continuous decline of macromechanical strength, accompanied by the formation, development, and penetration of slip surface (Figure 12). For slowly changing rock slopes with time-dependent deformation characteristics, the sliding surface of such slopes gradually evolved over a long period of time. For slopes with progressive deformation caused by excavation and unloading, if no controllable structural surface existed, the development of deep sliding surfaces would end in the early or middle stage of development, without entering the final stage of large-scale cumulative damage. Conversely, if the deformation was fully developed, the sliding surface evolution would have entered an irreversible state. At present, the left slope of the spillway tunnel exit is still in the stage of slow deformation, while no uniform potential sliding surface was formed. The characteristics of the left-side slope of the Wudongde spillway tunnel exit included (1) soft foundation effect, (2) antitilt cutting of fault $\mathrm{F}_{6}$, (3) high and steep slope formed by excavation, (4) high unloading relaxation depth, (5) relaxation deterioration of "locking section" at the slope middle, (6) nonuniform differential deformation, and (7) lower deformed rock mass pulling the upper slope to settle.

6.2. Analysis of Deformation Mechanism. The excavation mechanical response model of the left-side slope at the outlet of the spillway tunnel was mainly controlled by factors, such as the lithology of the slope, rock mass structure, excavation slope shape, excavation unloading scale, and construction disturbance effect. According to the geological conditions revealed by the excavation of the slope, the upper part was 

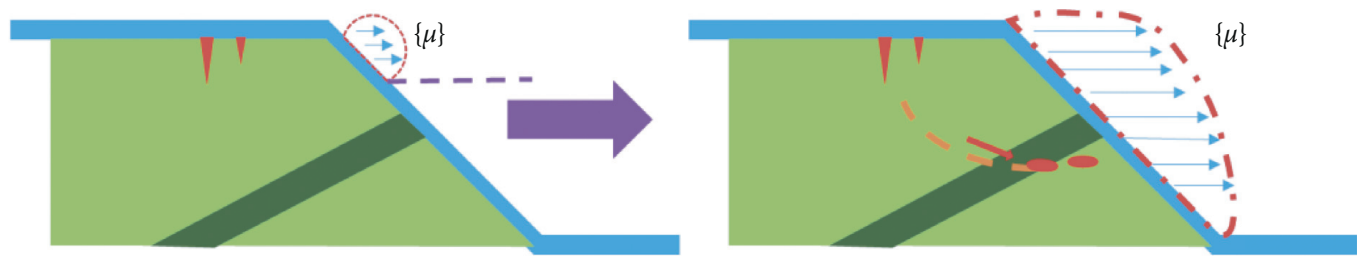

(a)

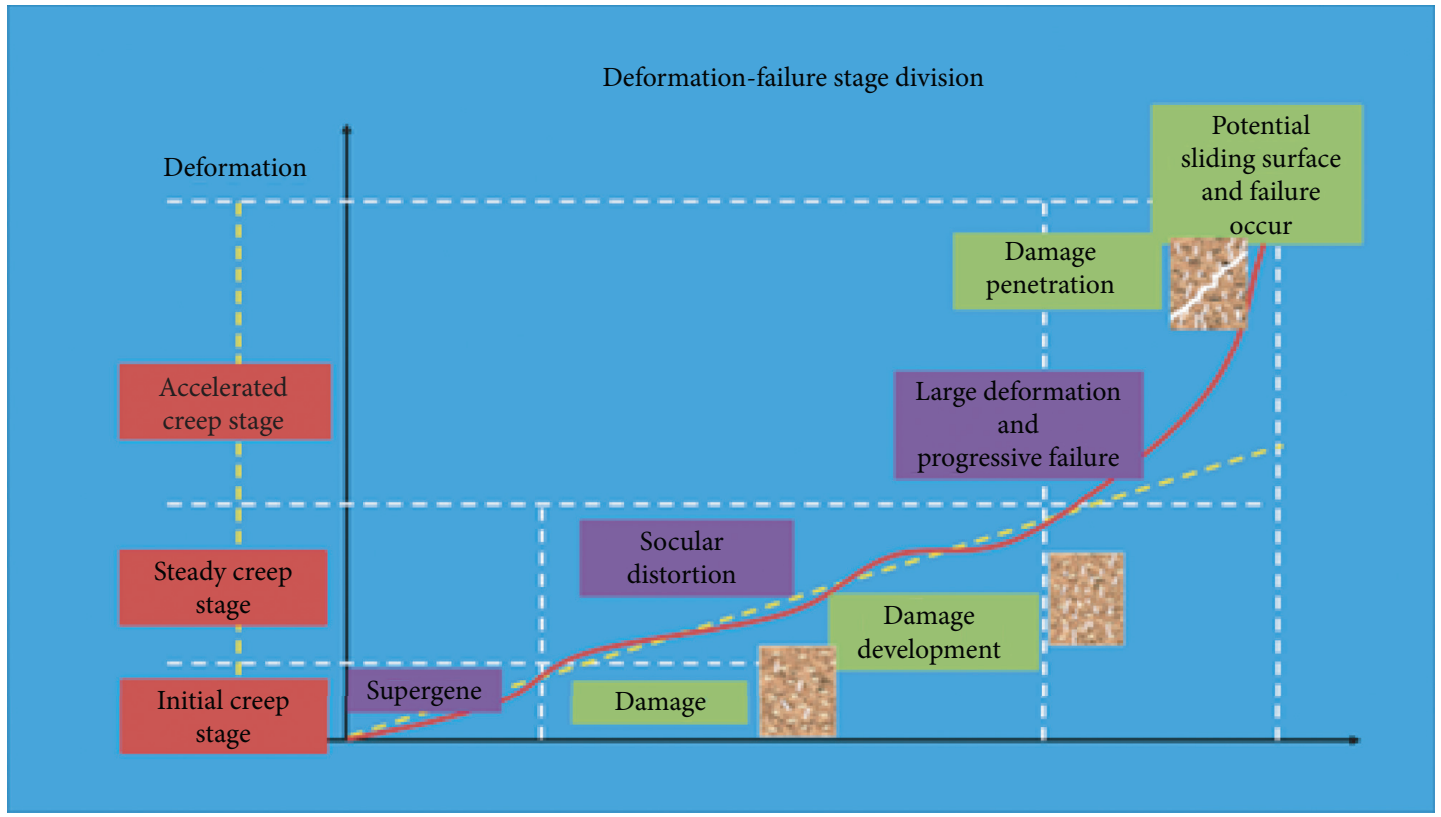

(b)

Figure 12: Deformation-failure evolution of slope.

thin dolomite interspersed with sandy mudstone, shale, and thick dolomite, while the lower part was thin dolomite and limestone. A large-scale fault $\mathrm{F}_{6}$ existed within the slope, and the trend was NNW $160^{\circ} \sim 180^{\circ}$. Plastic shale debris was often found near the main section. The mass of the slope rock mass was mainly $\mathrm{IV}_{2}$ and $\mathrm{IV}_{1}$, while the low amount was $\mathrm{III}_{2}, \mathrm{III}_{1}$, and $\mathrm{V}$. The slope unloading relaxation zone was generally $21.4 \mathrm{~m}$ deep, and the deepest part was at $29.2 \mathrm{~m}$.

The main causes of slope deformation included the following:

(1) Internal cause 1: due to the soft foundation effect, the rock mass had poor lithology, as well as a wide range of unloading relaxation, while the quality of rock mass was apparently reduced. The rock mass quality of slope was mainly $\mathrm{IV}_{2}$ and $\mathrm{IV}_{1}$ (Figure 13), a portion of which was $\mathrm{III}_{2}$. Geophysical detection of slope demonstrated that the acoustic wave in relaxation zone was $2.5 \mathrm{~km} / \mathrm{s}$ to $3.2 \mathrm{~km} / \mathrm{s}$, the acoustic wave in nonrelaxation zone was $3.0 \mathrm{~km} / \mathrm{s}$ to $4.5 \mathrm{~km} / \mathrm{s}$, and the local area was $3.0 \mathrm{~km} / \mathrm{s}$ to $5.0 \mathrm{~km} / \mathrm{s}$. A "soft foundation effect" existed within the lower part of the slope to a certain extent, while similar deformation features often appeared on the slope of the "upper hard and softer" structure

(2) Internal cause 2: cutting and weakening effects of fault $\mathrm{F}_{6}$ and caprock $\mathrm{Z}_{2 \mathrm{~g}}$ on slope. The fault strike of
$\mathrm{F}_{6}$ intersected with the slope strike at a high angle, steeply leaning into the slope, demonstrating an antidipping rock mass structure. $\mathrm{F}_{6}$ was a normal fault, the caprock was staggered, the vertical offset was approximately $420 \mathrm{~m}$, and the main fault zone was composed of mud-clastic. Field monitoring demonstrated that the highly deformed part of the slope and the large stress part of the anchor cable were located at the hanging wall and foot wall area of fault $\mathrm{F}_{6}$. The numerical calculation demonstrated that along with the gradual exposure of $\mathrm{F}_{6}$ on the slope surface, the downstream side slope of the fault and the upstream side slope (rock mass connected with front slope of spillway tunnel) were separated to form a weak boundary of the downstream side slope of the fault, which weakened the three-dimensional side restraint effect of the front slope of the spillway tunnel on the entire left side of the slope. The deformation of downstream side slope of fault $\mathrm{F}_{6}$ extruded the fault and its footwall slope, demonstrating the self-compression of the weak part of the fault and the deformation slip towards the outside side of the slope. Also, the phenomena of high lateral deformation and low internal deformation of the unloading deformation of the hanging wall and foot wall itself were apparent. The upstream side slope bore the compressive load transmitted through the 


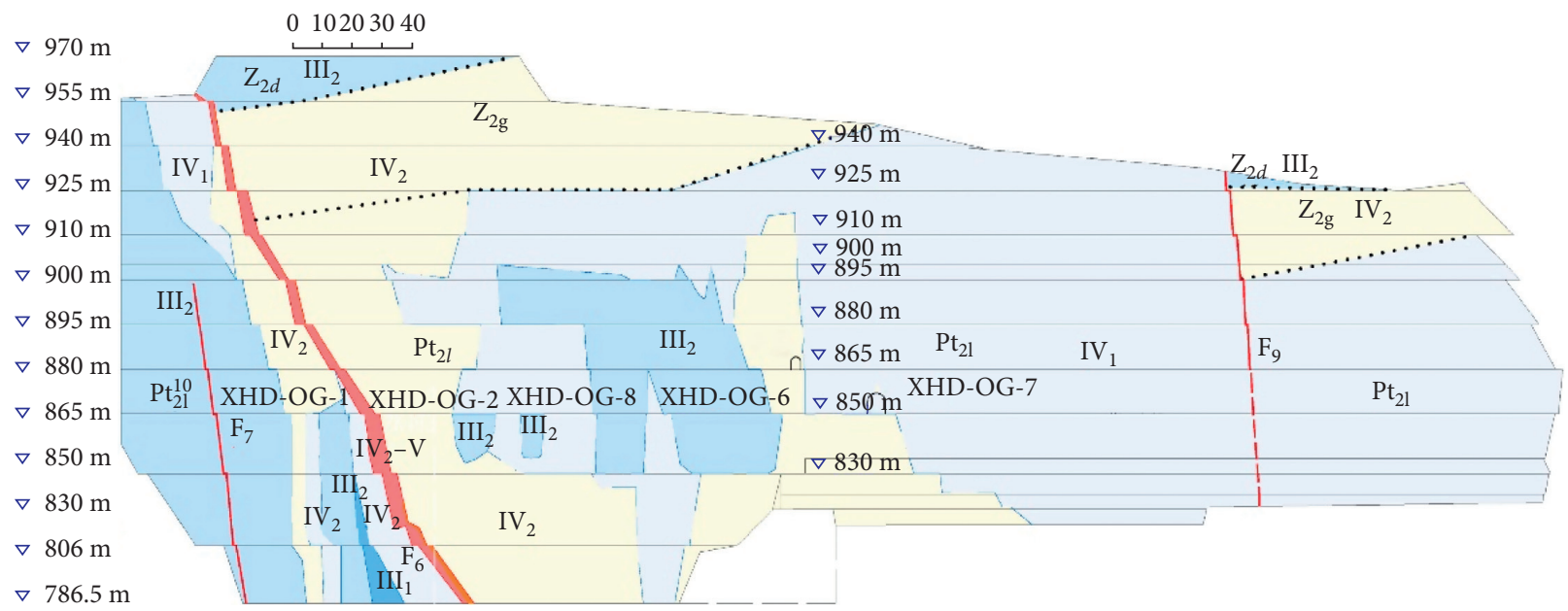

FIGURE 13: Distribution map of main strata.

fault, while the slope connected with the front slope of the spillway tunnel acted as support and impedance to the fault expansion and its downstream side slope. In addition, the Guanyinya formation was a rock mass with poor integrity and low deformation modulus, while the joint weakening with the $\mathrm{F}_{6}$ fault also affected the slope deformation of local convex terrain near the slope opening line

(3) External cause: the scope and depth of excavation unloading relaxation were high, the scope of slope excavation unloading disturbance was high, and the unloading speed was high. The wave velocity decreased along the hole depth, and, in part, continuous low-wave-velocity zones existed in the interior, except the surface relaxation zone of the slope. The strong unloading relaxation depth of the slope was high, while the relaxation zone was generally $21.4 \mathrm{~m}$ and the deepest point was at $29.2 \mathrm{~m}$. A high amount of new cracks occurred within the deep rock mass, and the local continuous distribution led to the wave velocity reduction zone, which caused the overall wave velocity to be low and the relaxation zone to be high. With time stress adjustment, crack initiation, evolution, and continuous propagation were caused. The relaxation zone extended towards the depth with excavation, while the quality and mechanical parameters of rock mass were deteriorated.

For example, the long hole acoustic wave test at an elevation of $853 \mathrm{~m}$ shows that between June 2016 and November 2016 , the test relaxation depth is about $2.5 \mathrm{~m}$, and the average acoustic wave velocity of the rock mass in the relaxation zone is $3100 \mathrm{~m} / \mathrm{s} \sim 3300 \mathrm{~m} / \mathrm{s}$. After the slope was excavated from $830 \mathrm{~m}$ elevation to $806 \mathrm{~m}$ elevation, the relaxation depth became significantly larger. The relaxation depth tested on May 6, 2017 reached $11.8 \mathrm{~m}$, and the average acoustic wave velocity of the rock mass in the relaxation zone was $2500 \mathrm{~m} / \mathrm{s} \sim 2900 \mathrm{~m} / \mathrm{s}$. The relaxation depth is shown in Figure 14. During the blasting operation on the slope, the instantaneous strong dynamic load disturbance caused the reduction of rock mass properties,

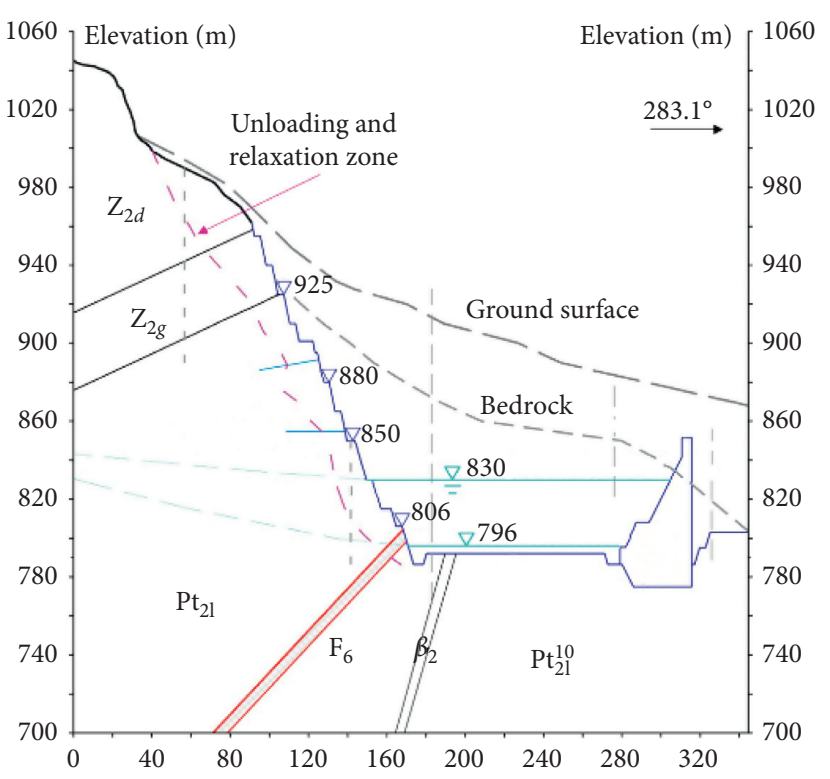

FIGURE 14: Unloading relaxation zone within the middle of slope.

especially the faults and areas with poor lithology quality, which caused the sudden increase of deformation in these areas in a short time. As shown in Figure 15, when performing blasting operations at an altitude of $830 \mathrm{~m}$, the M14 multipoint displacement gauge is located at an altitude of $850 \mathrm{~m}$, which is close to the blasting operation point and fault, and the rock mass quality level of this area is low, so it caused a sudden change in slope displacement in this area. However, the M13 multipoint displacement gauge is located at an elevation of $880 \mathrm{~m}$, relatively far from the blasting operation point and fault, and the rock mass quality level in this area is relatively high, so although the increase in displacement occurs, the increase in displacement is relatively low. At the same time, after the lower rock mass is excavated, the support effect of the lower rock mass on the upper rock mass is significantly reduced, which will also increase the overall deformation of the upper rock mass. 


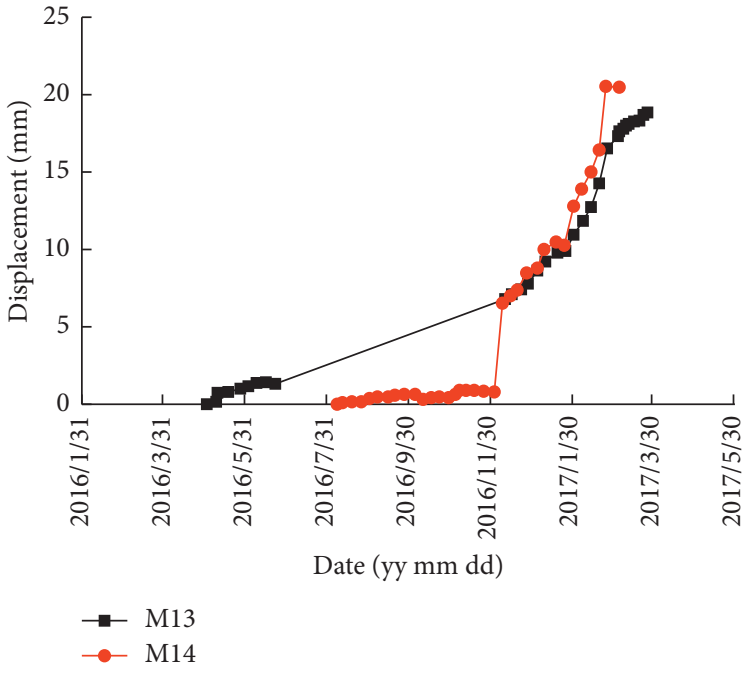

(a)

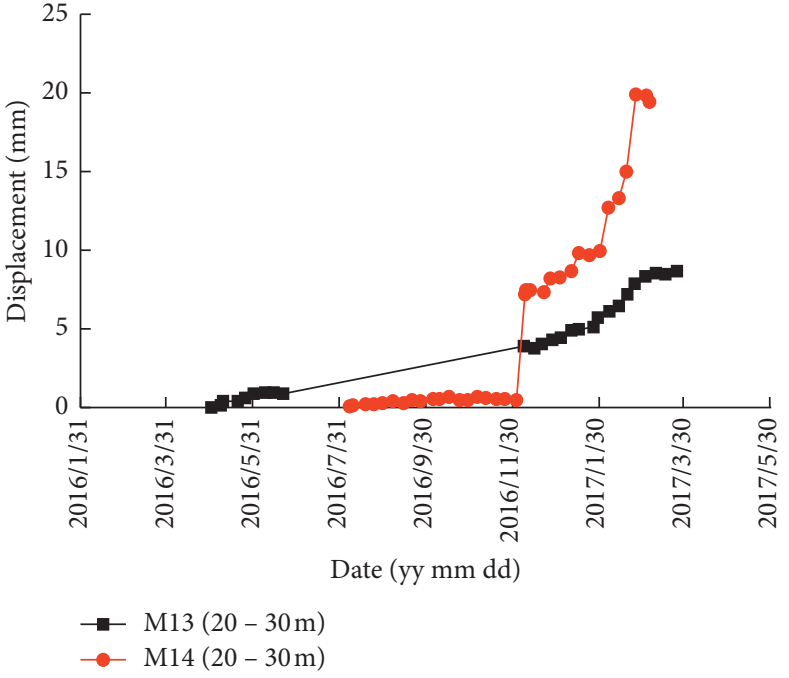

(b)

Figure 15: Evolution characteristics of upper surface and deep deformation at the middle of slope. (a) Variation of surface deformation at the middle of slope with time. (b) Variation of deep deformation at the middle of slope with time.

In summary, the geological conditions of the left-side slope at the outlet of Wudongde spillway tunnel were complex, and the rock mass quality was poor. Under the condition of rapid excavation and unloading, the relaxation deformation depth of rock mass exceeded the general rock slope relaxation deformation depth. The slope deformation and the stress increment of anchor cables were generally high, which had an adverse effect on the slope stability. With the excavation of slope engineering, corresponding measures should be taken to improve the overall stability of the left-side slope.

6.3. Reinforcement and Treatment. With the continuous excavation of the later slope engineering, the stability of the slope would still be reduced under the influence of engineering disturbance under the current conditions. Therefore, corresponding measures should be taken to improve the overall stability of the slope. It was suggested that unbonded prestressed anchor cables should be added in the area, where the slope deformation and anchor cable overload could occur within the range from $850 \mathrm{~m}$ to the opening line of engineering slope to strengthen anchorage. Moreover, overload anchor cables should be loosened, and the deformation of slope under continuous excavation could be reduced. The concrete should be sprayed upon the slope near the $\mathrm{F}_{6}$ fault, while the cracked and broken rock mass should be cleaned up, while the steel mesh should be hang and the concrete should be sprayed. Anchor rods of the system were arranged near the fault, perpendicularly to the surface of the slope, which were tied tightly with the reinforcement of the hanging net, while the drainage holes of the system increased. A certain number of anchor holes should be selected for borehole acoustic wave and borehole color TV detection in the construction of new anchor cables in the engineering slope area. In addition, a certain number of anchor cable dynamometers should be arranged. Also, the constant resistance and high deformation monitoring anchor cables should be added to the large deformation area to realize the intelligent and dynamic monitoring of the anchor cable force within the slope.

\section{Conclusions}

Based on the above analysis, a few conclusions can be drawn:

(1) Combined with the recommended values of rock mass mechanical parameters and slope safety monitoring results, the rock mass mechanical parameters were obtained through inversion analysis.

(2) The numerical simulation results demonstrated that after the excavation is completed, the larger slope deformation area is distributed in the hanging and foot wall of fault $F_{6}$ and the grade $\mathrm{IV}_{2}$ rock mass below $830 \mathrm{~m}$ elevation, and the deformation of the hanging wall rock mass is significantly greater than that of the foot wall, and the maximum deformation range is $350 \mathrm{~mm} 380 \mathrm{~mm}$. The depth of stress disturbance is $30 \mathrm{~m} \sim 60 \mathrm{~m}$, and there is a certain degree of stress concentration at the foot of slope; the stress level is about $2 \mathrm{MPa} \sim 5 \mathrm{MPa}$. The plastic zone of the slope is concentrated in the fault $\mathrm{F}_{6}$ fracture zone and the area with poor rock mass, and the rock mass of the slope basically entered into the plastic state, mainly demonstrating compressive shear failure.

(3) The internal cause of the deformation mechanism is the overall poor quality of the slope rock mass, which is represented by the structure of "upper hard and lower soft." At the same time, fault $\mathrm{F}_{6}$ and stratum $Z_{2 g}$ have the effect of cutting and weakening the slope. The external factors are the large unloading 
relaxation range, depth and disturbance range, and the fast unloading speed.

(4) As the slope project continues to advance, the stability of the slope will still decrease, so the corresponding treatment measures such as slowing slope ratio, consolidation grouting, and deep anchor cable support are recommended below $806 \mathrm{~m}$. At the same time, it is proposed to use the remote sliding force monitoring system to monitor the sliding force at the deep part of the slope in real time, which will provide an effective reference for the stability assessment and treatment of the slope of the hydropower station.

\section{Data Availability}

The data are all available and have been explained in this article. Readers can access the data supporting the conclusions of the study.

\section{Conflicts of Interest}

The authors declare that no conflicts of interest exit regarding the submission of this paper.

\section{Acknowledgments}

This study was supported by the Open Funds of the State Key Laboratory for Geomechanics and Deep Underground Engineering (no. SKLGDUEK1819).

\section{References}

[1] Y. Zhang, S. Cao, N. Zhang, and C. Zhao, "The application of short-wall block backfill mining to preserve surface water resources in northwest China," Journal of Cleaner Production, vol. 261, Article ID 121232, 2020.

[2] N. Zhang, W. Liu, Y. Zhang, P. Shan, and X. Shi, "Microscopic pore structure of surrounding rock for underground strategic petroleum reserve (SPR) caverns in bedded rock salt," Energies, vol. 13, no. 7, p. 1565, 2020.

[3] N. Jiang, C. Wang, H. Pan, D. Yin, and J. Ma, "Modeling study on the influence of the strip filling mining sequence on mining-induced failure," Energy Science \& Engineering, vol. 8, no. 6, pp. 2239-2255, 2020.

[4] G. Feng, Y. Kang, X. Wang, Y. Hu, and X. Li, "Investigation on the failure characteristics and fracture classification of shale under brazilian test conditions," Rock Mechanics and Rock Engineering, vol. 53, no. 7, pp. 3325-3340, 2020.

[5] D. Ren, D. Zhou, D. Liu, F. Dong, S. Ma, and H. Huang, "Formation mechanism of the upper triassic Yanchang formation tight sandstone reservoir in ordos basin-take chang 6 reservoir in Jiyuan oil field as an example," Journal of Petroleum Science and Engineering, vol. 178, pp. 497-505, 2019.

[6] S. Chen, D. Yin, N. Jiang, F. Wang, and Z. Zhao, "Mechanical properties of oil shale-coal composite samples," International Journal of Rock Mechanics and Mining Sciences, vol. 123, Article ID 104120, 2019.

[7] N. W. Xu, C. A. Tang, L. C. Li et al., "Microseismic monitoring and stability analysis of the left bank slope in Jinping first stage hydropower station in southwestern China," International Journal of Rock Mechanics and Mining Sciences, vol. 48, no. 6, pp. 950-963, 2011.
[8] C. Zhu, M. C. He, M. Karakus, X. B. Cui, and Z. G. Tao, "Investigating toppling failure mechanism of anti-dip layered slope due to excavation by physical modelling," Rock Mechanics and Rock Engineering, vol. 2020, pp. 1-20, 2020.

[9] L. H. Wang and J. L. Bai, "Analyze of the affection of excavation unloading of the rock mass of the spillway tunnel of a hydropower station on the slope's stability," Advanced Materials Research, vol. 594-597, pp. 621-626, 2012.

[10] Q. T. Pei, H. B. Li, Y. Q. Liu, and J. G. Jiang, "Influence of slope gradient on distribution rule of geostress field in river valleys," Applied Mechanics and Materials, vol. 404, pp. 365-370, 2013.

[11] Z. Z. Shen, Y. F. Sun, L. Q. Xu, and N. Wang, "Safety analysis of plant slope of Haokou power station," Applied Mechanics and Materials, vol. 620, pp. 382-385, 2014.

[12] G. Li, M. He, G. Zhang, and Z. Tao, "Deformation mechanism and excavation process of large span intersection within deep soft rock roadway," Mining Science and Technology (China), vol. 20, no. 1, pp. 28-34, 2010.

[13] P. Shan and X. Lai, "An associated evaluation methodology of initial stress level of coal-rock masses in steeply inclined coal seams, Urumchi coal field, China," Engineering Computations, vol. 37, no. 6, pp. 2177-2192, 2020.

[14] Q. Zhan, X. Sun, C. Li et al., "Stability analysis and reinforcement of a high-steep rock slope with faults: numerical analysis and field monitoring," Advances in Civil Engineering, vol. 2019, Article ID 3732982, 8 pages, 2019.

[15] G. Feng, X. C. Wang, M. Wang, and Y. Kang, "Experimental investigation of thermal cycling effect on fracture characteristics of granite in a geothermal-energy reservoir," Engineering Fracture Mechanics, vol. 235, Article ID 107180, 2020.

[16] C. X. Wang, B. T. Shen, J. T. Chen et al., "Compression characteristics of filling gangue and simulation of mining with gangue backfilling: an experimental investigation," Geomechanics and Engineering, vol. 20, no. 6, pp. 485-495, 2020.

[17] H. Huang, T. Babadagli, X. Chen, H. Li, and Y. Zhang, "Performance comparison of novel chemical agents for mitigating water-blocking problem in tight gas sandstones," SPE Reservoir Evaluation \& Engineering, pp. 1-9, 2020.

[18] Z. Li and X. J. Liang, "Stability generalized analysis of a largescale accumulation body slope," Applied Mechanics and Materials, vol. 170-173, pp. 1124-1129, 2012.

[19] Q. Yin, G. Ma, H. Jing et al., "Hydraulic properties of 3D rough-walled fractures during shearing: an experimental study," Journal of Hydrology, vol. 555, pp. 169-184, 2017.

[20] R. Huang, H. Xiao, N. Ju, and J. Zhao, "Deformation mechanism and stability of a rocky slope," Journal of China University of Geosciences, vol. 18, no. 1, pp. 77-84, 2007.

[21] D. K. Liu, Z. L. Gu, R. X. Liang et al., "Impacts of pore-throat system on fractal characterization of tight sandstones," Geofluids, vol. 2020, no. 9, Article ID 4941501, 17 pages, 2020.

[22] Y. D. Meng and W. Y. Xu, "Analysis of 3D visualization of safety monitoring for complicated high rock slope engineering," Chinese Journal of Rock Mechanics and Engineering, vol. 29, no. 12, pp. 2500-2509, 2010, in Chinese.

[23] J. Zhang and W. Xu, "Safety monitoring and stability analysis of large-scale and complicated high rock slope," Chinese Journal of Rock Mechanics and Engineering, vol. 28, no. 09, pp. 1819-1827, 2009, in Chinese.

[24] L. H. Wang, J. L. Li, S. S. Yang, Z. Cheng, and M. Zhu, "Back analysis about shear strength and deformation parameters of high excavated accumulation slope in Xiaowan hydropower station," Advanced Materials Research, vol. 255-260, pp. 3482-3487, 2011. 
[25] L. F. Zou, W. Y. Xu, and C. Shi, "Three dimensional numerical analysis of deformation and stability of zone II of Xiazanri slope deposit," Applied Mechanics and Materials, vol. 90-93, pp. 2372-2379, 2011.

[26] T. Wang, H. Wu, Y. Li et al., "Stability analysis of the slope around flood discharge tunnel under inner water exosmosis at Yangqu hydropower station," Computers and Geotechnics, vol. 51, pp. 1-11, 2013.

[27] Y. Li, H. Zhou, W. Zhu, S. Li, and J. Liu, "Numerical investigations on slope stability using an elasto-brittle model considering fissure water pressure," Arabian Journal of Geosciences, vol. 8, no. 12, pp. 10277-10288, 2015.

[28] X. Liu, C. A. Tang, L. Li, P. Lv, and R. Sun, "Microseismic monitoring and stability analysis of the right bank slope at Dagangshan hydropower station after the initial impoundment," International Journal of Rock Mechanics and Mining Sciences, vol. 108, pp. 128-141, 2018.

[29] K. Ma, N. W. Xu, and Z. Z. Liang, "Stability assessment of the excavated rock slope at the Dagangshan hydropower station in China based on microseismic monitoring," Advances in Civil Engineering, vol. 2018, Article ID 4567258, 16 pages, 2018.

[30] B. Maihemuti, E. Wang, T. Hudan et al., "Numerical simulation analysis of reservoir bank fractured rock-slope deformation and failure processes," International Journal of Geomechanics, vol. 16, no. 2, Article ID 04015058, 2016.

[31] T. Chen, J. Deng, N. Sitar et al., "Stability investigation and stabilization of a heavily fractured and loosened rock slope during construction of a strategic hydropower station in China," Engineering Geology, vol. 221, pp. 70-81, 2017.

[32] S. Qi, F. Wu, Y. Zhou, Y. Song, and M. Gong, "Influence of deep seated discontinuities on the left slope of Jinping I hydropower station and its stability analysis," Bulletin of Engineering Geology and the Environment, vol. 69, no. 3, pp. 333-342, 2010.

[33] L. Zhang, Q. Yang, and Y. Liu, "Long-term stability analysis of the left bank abutment slope at Jinping I hydropower station," Journal of Rock Mechanics and Geotechnical Engineering, vol. 8, no. 3, pp. 398-404, 2016.

[34] R. Wang and W. Xu, "Numerical analysis of long-term stability of left bank abutment high slope at Jinping I hydropower station," Chinese Journal of Rock Mechanics and Engineering, vol. 33, no. 3, pp. 105-3113, 2014, in Chinese.

[35] S. C. Hu, Y. L. Tan, H. Zhou et al., "Anisotropic modeling of layered rocks incorporating planes of weakness and volumetric stress," Energy Science \& Engineering, vol. 8, no. 3, pp. 789-803, 2020.

[36] N. Xu, F. Dai, Z. Zhou, P. Jiang, and T. Zhao, "Microseismicity and its time-frequency characteristics of the left bank slope at the Jinping first-stage hydropower station during reservoir impoundment," Environmental Earth Sciences, vol. 75, no. 7, p. 608, 2016.

[37] X. Wang, W. Yuan, Y. T. Yan, and X. Zhang, "Scale effect of mechanical properties of jointed rock mass: a numerical study based on particle flow code," Geomechanics and Engineering, vol. 21, no. 3, pp. 259-268, 2020.

[38] Y. Liu, J. Xiang, H. Huang et al., "Stability control based excavation of left bank slope at Jinping-1 hydropower station," Electronic Journal of Geotechnical Engineering, vol. 19, pp. 17643-17656, 2014.

[39] L. Dong, Y. Yang, B. Qian, Y. Tan, H. Sun, and N. Xu, "Deformation analysis of large-scale rock slopes considering the effect of microseismic events," Applied Sciences, vol. 9, no. 16, p. 3409, 2019. 